\title{
The effects of biogeochemical processes on oceanic conductivity/ salinity/density relationships and the characterization of real seawater
}

\author{
R. Pawlowicz ${ }^{1}$, D. G. Wright ${ }^{2, \dagger}$, and F. J. Millero ${ }^{3}$ \\ ${ }^{1}$ Dept. of Earth and Ocean Sciences, University of British Columbia, Vancouver, B.C., V6T 1Z4, Canada \\ ${ }^{2}$ Bedford Institute of Oceanography, Dartmouth, N.S., B2Y 4A2, Canada \\ ${ }^{3}$ Rosenstiel School of Marine and Atmospheric Science, University of Miami, Miami, Fl 33149, USA \\ $\dagger$ deceased
}

Received: 24 March 2010 - Published in Ocean Sci. Discuss.: 7 April 2010

Revised: 22 April 2011 - Accepted: 18 May 2011 - Published: 1 June 2011

\begin{abstract}
As seawater circulates through the global ocean, its relative composition undergoes small variations. This results in changes to the conductivity/salinity/density relationship, which is currently well-defined only for Standard Seawater obtained from a particular area in the North Atlantic. These changes are investigated here by analysis of laboratory experiments in which salts are added to seawater, by analysis of oceanic observations of density and composition anomalies, and by mathematical investigation using a model relating composition, conductivity, and density of arbitrary seawaters. Mathematical analysis shows that understanding and describing the effect of changes in relative composition on operational estimates of salinity using the Practical Salinity Scale 1978 and on density using an equation of state for Standard Seawater require the use of a number of different salinity variables and a family of haline contraction coefficients. These salinity variables include an absolute Salinity $S_{\mathrm{A}}^{\text {soln }}$, a density salinity $S_{\mathrm{A}}^{\text {dens }}$, the reference salinity $S_{\mathrm{R}}$, and an added-mass salinity $S_{\mathrm{A}}^{\text {add }}$. In addition, a new salinity variable $S_{*}$ is defined, which represents the preformed salinity of a Standard Seawater component of real seawater to which biogeochemical processes add material. In spite of this complexity, observed correlations between different ocean biogeochemical processes allow the creation of simple formulas that can be used to convert between the different salinity and density measures, allowing for the operational reduction of routine oceanographic observations.
\end{abstract}

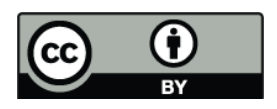

Correspondence to: R. Pawlowicz (rich@eos.ubc.ca)

\section{Introduction}

Traditionally, the density $\rho$ of IAPSO Standard Seawater (SSW), obtained from a particular area in the North Atlantic, is not routinely measured directly but instead is estimated using a mathematical function of state variables for temperature $t$, sea pressure $p$, and a salinity $S_{\text {state }}$ :

$\rho=f\left(S_{\text {state }}, t, p\right)$

The empirical function $f(\cdot)$ and the free variables have been defined for many years by the 1980 equation of state, (EOS80; UNESCO, 1981a), and will in future be specified by the 2010 thermodynamical equation of state (TEOS-10; IOC et al., 2010). The salinity state variable $S_{\text {state }}$ is used to parameterize the effects of dissolved material within the water, and in addition to acting as a state variable in Eq. (1) is also traditionally used as a measure of the actual amount of dissolved material. Numerical values of $S_{\text {state }}$ are defined to be close to the mass fraction of solute.

However, salinity itself is not easy to define precisely and the history of its definition and operational determination is complex (Lewis and Perkin, 1978; Millero et al., 2008a). Salinity is currently determined by measurements of electrical conductivity, which varies with the ionic content. The relationship between conductivity $\kappa$ and a so-called Practical Salinity $S_{\mathrm{P}}(\kappa, t, p)$ in Standard Seawater is specified by the Practical Salinity Scale 1978 (PSS-78, UNESCO, 1981b).

Practical Salinity $S_{\mathrm{P}}$ is the salinity state variable defined for use in Eq. (1) by EOS-80. Under TEOS-10 the salinity state variable is chosen to be a better estimate of the solution absolute salinity (or absolute salinity) $S_{\mathrm{A}}^{\text {soln }}$ of the seawater

Published by Copernicus Publications on behalf of the European Geosciences Union. 
solution. Absolute salinity is the mass fraction of dissolved material contained within a sample of seawater at reference conditions $\left(t=25^{\circ} \mathrm{C}\right.$ and sea pressure $\left.p=0 \mathrm{~Pa}\right)$ :

$S_{\mathrm{A}}^{\mathrm{soln}}=s(C)=\sum_{i=1}^{N_{c}} M_{i} c_{i}$

where $c_{i}$ are the concentrations in moles per kilogram of solution (referred to as molonities) of the $N_{c}$ individual constituents, collectively labelled as the composition $C=$ $\left\{c_{1}, c_{2}, \ldots, c_{N_{c}}\right\}$, and the $M_{i}$ are the molar masses of each constituent. The form $s(\cdot)$ will henceforth be used to represent this type of summation.

Under TEOS-10 a defined Reference Composition (Millero et al., 2008a) is taken as the best estimate of the chemical composition of SSW. For seawater with Reference Composition the numerical value of the absolute salinity is called the Reference Salinity $\left(S_{\mathrm{R}}\right)$. The operational determination of Reference Salinity for SSW, as measured using conductivity within the range of validity of PSS-78, is linked to the definition of absolute salinity by a relationship

$S_{\mathrm{R}}=\gamma \times S_{\mathrm{P}}$

where the scale factor $\gamma$ is chosen to give the correct absolute salinity on the Reference Composition Scale for a SSW of a given Practical Salinity. The scale factor $\gamma$ is therefore numerically specified to be $u_{\mathrm{PS}} \equiv(35.16504 / 35) \mathrm{g} \mathrm{kg}^{-1}$, because the absolute salinity computed from the Reference Composition for seawater with $S_{\mathrm{P}}=35$ is $35.16504 \mathrm{~g} \mathrm{~kg}^{-1}$. This definition produces the correct numerical argument for the TEOS-10 equation of state. To remain consistent with the numerical formulation of this equation of state, $u_{\mathrm{PS}}$ must remain fixed even if more accurate information about the composition of SSW is known (Wright et al., 2011).

Irrespective of the exact composition of SSW, as seawater circulates through the world oceans, its composition will be altered by biogeochemical processes. The conductivity/salinity/density relationships of this water will be different than those of SSW. Thus not only will $S_{\mathrm{R}}$ obtained using Eqn. (3) with $\gamma=u_{\mathrm{PS}}$ be a biased estimate of $S_{\mathrm{A}}^{\text {soln }}$, i.e.,

$S_{\mathrm{A}}^{\text {soln }}=S_{\mathrm{R}}+\delta S_{\mathrm{R}}^{\text {soln }}$

with a nonzero salinity anomaly $\delta S_{\mathrm{R}}^{\text {soln }}$, but density calculated from Eq. (1) using this $S_{\mathrm{R}}$ as the argument may be in error. The approximate magnitude of these errors is known (Brewer and Bradshaw, 1975; Millero et al., 1978) but their effects were deemed operationally unimportant during the standardization of PSS-78 and EOS-80 (Lewis and Perkin, 1978). Real seawater was treated as if it was SSW.

However, the differences are measurable, and providing suitable corrections is now desirable. During the development of TEOS-10, direct measurements of density anomalies, i.e. the differences $\delta \rho_{\mathrm{R}}$ between calculated and measured densities, were converted into estimates of a salinity anomaly $\delta S_{\mathrm{R}}^{\text {dens }}$ using:

$\delta S_{\mathrm{R}}^{\mathrm{dens}} \equiv \frac{\delta \rho_{\mathrm{R}}}{\rho \beta_{\mathrm{R}}} \approx \frac{\delta \rho_{\mathrm{R}}}{\rho\left[0.735\left(\mathrm{gg}^{-1}\right)\right]}$

(Millero, 2000; Millero et al., 2008a; McDougall et al., 2009), where the haline contraction coefficient for Standard Seawater, $\beta_{\mathrm{R}}$, is related to the slope of the salinity/density relationship and is defined from Eq. (1) as

$\beta_{\mathrm{R}} \equiv \frac{1}{\rho} \frac{\partial \rho}{\partial S_{\mathrm{R}}}$

Then $S_{\mathrm{R}}$ in the TEOS-10 equation of state can be replaced with a density salinity $S_{\mathrm{A}}^{\text {dens }}=S_{\mathrm{R}}+\delta S_{\mathrm{R}}^{\text {dens }}$ to correctly estimate the density of any ocean water. This procedure is based on the use of salinity as a state variable for the density of seawater. If density changes in seawater are approximately dependent only on changes in the mass of dissolved material, irrespective of its composition, which has been found to be true in many cases involving natural waters (Millero, 1975; Chen and Millero, 1986), then $S_{\mathrm{A}}^{\text {dens }}$ would also be a good measure of $S_{\mathrm{A}}^{\text {soln }}$. Anticipating this, the value computed by Eq. (5), denoted $\delta S_{\mathrm{R}}^{\text {dens }}$ here, was denoted $\delta S_{\mathrm{A}}$ in Millero et al. (2008a) and McDougall et al. (2009), with the symbol $S_{\mathrm{A}}$ being used to represent both $S_{\mathrm{A}}^{\text {soln }}$ and $S_{\mathrm{A}}^{\text {dens }}$.

However, an alternative approach to quantifying the salinity anomaly in real ocean seawater is to directly estimate it with an equation similar to Eq. (2). Not all constituents need to be individually measured. In practise, measurements of conductivity and of the concentrations of constituents in seawater whose amounts vary due to biogeochemical processes are sufficient (Pawlowicz, 2010) to estimate $\delta S_{\mathrm{R}}^{\text {soln }}$. This approach, based on the use of salinity as a measure of dissolved content, results in somewhat larger numerical values for $\delta S_{\mathrm{R}}^{\text {soln }}$ than are found for $\delta S_{\mathrm{R}}^{\text {dens }}$ in the same situations (Brewer and Bradshaw, 1975; Pawlowicz, 2010). This implies that $S_{\mathrm{A}}^{\mathrm{soln}}$ will be larger than $S_{\mathrm{A}}^{\text {dens }}$.

Since both roles of salinity, as a density state variable and as a measure of dissolved material, are important, it is necessary to understand the disagreement between the two approaches. The purpose of this paper is then to investigate composition-dependent changes in conductivity/salinity/density relationships in seawater, to determine their effects on the haline contraction coefficient, and to propose methods of providing corrections for these changes. Although all results in this paper involve calculations at atmospheric pressure, or comparisons with laboratory measurements made at atmospheric pressure, it is assumed that pressure effects on these anomaly calculations are small. The results will then be useful in attempts to understand observations and develop models of the large-scale ocean circulation.

In order to accomplish this, a numerical model relating composition, conductivity, and density in seawater affected by biogeochemical processes is developed (Sect. 2). Composition/conductivity effects have already been investigated 
(Pawlowicz, 2010). Here equations are formally developed to model the density of natural waters of arbitrary composition (Sect. 2.1). By taking appropriate derivatives of these equations, an analytical model for the haline contraction coefficient in cases of arbitrary compositional anomalies is determined (Sect. 2.2). The effects of compositional changes are discussed, both in cases of fixed chlorinity and in cases of fixed conductivity (Sect. 2.3). This requires the development of an appropriate notation. Chlorinity (Millero et al., 2008a) is a measure of the quantity of small subset of the conservative elements in seawater, and is an appropriate proxy for salinity in laboratory investigations and ocean modelling applications. However, since ocean observations are based on measurements of electrical conductivity, which is affected by all ions present (conservative and nonconservative), and not on measurements of density or constituent concentrations directly, it is important to consider means by which composition changes can be modelled at this fixed or measured conductivity. This requires determining an appropriate reduction in the concentrations of conservative components in a Standard Seawater of the measured conductivity, while nonconservative constituents undergo increases to measured levels. Finally, in order to make numerical calculations, a seawater composition model must be constructed, including both conservative and nonconservative components. We define a Standard Seawater composition (Sect. 2.4), a model for carbonate system equilibria, and a model for biogeochemical anomalies in the open ocean which satisfies charge balance requirements (Sect. 2.5).

Once the mathematical machinery is validated against laboratory measurements (Sects. 3.1 and 3.2), the effects of compositional changes are investigated for a test case representative of waters from the deep North Pacific (Sect. 3.3), and then for actual hydrographic profiles in various oceans (Sect. 3.5). Practical computations can be greatly simplified by the use of simple formulas. These simple formulas are created by regression against model calculations over a grid of composition anomalies (Sect. 3.4) Finally, model calculations are compared directly with the observational database of oceanic density anomalies $\delta \rho_{\mathrm{R}}$ (Sect. 3.6). This end-toend test of the model shows good agreement with the field observations and validates the conclusions.

\section{Theoretical background}

Theoretical development of equations modelling the haline contraction coefficient begins with a review of theory for the density of multicomponent electrolyte solutions, which is then differentiated with respect to salinity. Next, the theory is extended to model observational problems specifically involving seawater. Finally, in order to make numerical calculations a numerical model for the chemical composition of seawater and its anomalies is described.

\subsection{Aqueous solution density}

A kilogram of pure water containing an additional $S^{\prime}$ kilograms of solute has a density $\rho$, and its volume differs from the volume of a kilogram of pure water $1 / \rho_{0}$ by the apparent volume $V^{\prime}$ of the solute :

$\frac{1+S^{\prime}}{\rho}=\frac{1}{\rho_{0}}+V^{\prime}$

The solute concentration $S^{\prime}$ can be related to the more usual mass fraction salinity $S$ (kilograms per kilogram solution) by

$S=\sum_{i=1}^{N} M_{i} c_{i}=\frac{S^{\prime}}{1+S^{\prime}}$

where $M_{i}$ (units of $\mathrm{kg} \mathrm{mol}^{-1}$ ) is the molar mass of the $i$ th dissolved constituent, and $c_{i}$ its concentration (molonity) in units of mol $(\mathrm{kg} \mathrm{soln})^{-1}$. The molal concentration $c_{i}^{\prime}$ in units of mol (kg water $)^{-1}$ is related to $c_{i}$ by $c_{i}=(1-S) c_{i}^{\prime}$. Henceforth, primed and unprimed symbols will be used to distinguish between the two concentration scales when required for different variables. Calculation of density $\rho$ from a set of concentrations $c_{i}$ or $c_{i}^{\prime}$ thus reduces to calculation of $S^{\prime}$ (using Eq. 8) and $V^{\prime}$, followed by solution of Eq. (7):

$\rho=\rho_{0} \frac{1+S^{\prime}}{1+\rho_{0} V^{\prime}}=\frac{\rho_{0}}{1-S+\rho_{0} V}$

where $V=(1-S) V^{\prime}$.

The practical reason for proceeding in this way is that the apparent volume of solute in a multicomponent electrolyte can be modelled by extensions of an additivity property that holds for many binary electrolytes. The additivity property suggests that the apparent volume of a binary electrolyte is the sum of the apparent volumes of the two ionic components into which it dissociates (more precisely, apparent volumes are approximately the same no matter in which combination they occur in an arbitrary electrolyte). This property is uniformly valid at infinite dilution, and approximately true at low concentrations. A simple estimate for the apparent volume $V^{\prime}$ of a complex solute is then formed by adding together the apparent molal volumes $\phi_{i}$ (typically in units of $\mathrm{cm}^{3} \mathrm{~mol}^{-1}$ ) of its constituents, multiplied by their molal concentrations. These include components of the ionic part $V_{\text {I }}$ (composed of $N^{+}$cations and $N^{-}$anions), and of the nonionic part $V_{\mathrm{NI}}$ (composed of $N^{0}$ nonionic constituents) of the complete chemical composition:

$V^{\prime}=V_{\mathrm{I}}^{\prime}+V_{\mathrm{NI}}^{\prime}$

with

$V_{\mathrm{I}}^{\prime}=\sum_{i=1}^{N^{+}} \phi_{i}^{+}{c^{\prime}}_{i}^{+}+\sum_{i=1}^{N^{-}} \phi_{i}^{-} c_{i}^{{ }^{-}}$

and

$V_{\mathrm{NI}}^{\prime}=\sum_{i=1}^{N^{0}} \phi_{i}^{\circ}{c^{\prime \circ}}_{i}$ 
where the,+- and o superscripts indicate cation, anion, and neutral constituent values when they must be considered separately, and the $i$ subscript refers to values for single charged ions or neutral constituents. Note that apparent molal volumes can be negative as well as positive.

Ionic interactions between water and the different constituents will affect the $\phi_{i}$, and these effects can be modelled by a dependence on the stoichiometric ionic strength, calculated as a sum over the $N=N^{+}+N^{-}$different ions in solution:

$I^{\prime}=\frac{1}{2} \sum_{i=1}^{N} c^{\prime}{ }_{i} z_{i}^{2}$

where $z_{i}$ is the valence of charge associated with the $i$ th ion. For neutral constituents that do not dissociate into ions any dependence on ionic strength is due only to the presence of other ions in the solution.

It is not possible to experimentally separate the apparent molal volumes for cations and anions as all solutions remain in charge balance. However, apparent molal volumes for charge-balanced binary electrolytes $\phi_{j}\left(I^{\prime}\right)$ can be found from Eq. (7) by measurements of $\rho$ when $S^{\prime}$ is known. Here, we use a $j$ subscript to distinguish parameters referring to either neutral or charge-balanced binary electrolytes from the corresponding values for individual ions, which are subscripted with $i$. Experimental data for the apparent molal volumes of binary electrolytes and neutral dissolved substances at ionic strengths of zero to about $1.5 \mathrm{~mol} \mathrm{~kg}^{-1}$ are found in the literature. Polynomial fits are converted to the form

$\phi_{j}\left(I^{\prime}, t\right)=v_{j 0}+A_{j} \sqrt{I^{\prime}}+B_{j} I^{\prime}+C_{j} I^{\prime 3 / 2}+D_{j} I^{\prime 2}+E_{j} I^{\prime 5 / 2}$

where the coefficients are themselves functions of temperature $t /{ }^{\circ} \mathrm{C}$, i.e. $v_{j 0}=v_{j 0}^{(0)}+v_{j 0}^{(1)} t+v_{j 0}^{(2)} t^{2}+\ldots, A_{j}=A_{j}^{(0)}+$ $A_{j}^{(1)} t+A_{j}^{(2)} t^{2}+\ldots$, etc. Coefficients for different electrolytes and the sources of these coefficients are tabulated in Tables 2-4. Most sources parameterize in terms of the molalities $c_{j}^{\prime}$; these are converted to polynomials in $I^{\prime}=w_{j} c_{j}^{\prime}$, using Eq. (13) to determine the factor $w_{j}$, which is 1 for 1:1 electrolytes, 3 for 1:2 and 2:1 electrolytes, and 4 for $2: 2$ electrolytes. The disagreement between different literature sources for particular $\phi_{j}$, and the misfit in the polynomials, is typically in the range of $0.1 \mathrm{~cm}^{3} \mathrm{~mol}^{-1}$ to $1 \mathrm{~cm}^{3} \mathrm{~mol}^{-1}$.

When temperature dependence is not known (Table 4) we apply a simple temperature correction that falls within the range of temperature-dependence seen in electrolytes for which data is available:

$\phi_{j}\left(I^{\prime}, t\right)=\phi_{j}\left(I^{\prime}, 25^{\circ} \mathrm{C}\right)-0.002333 \times(t-25)(t-60)$

This approximation will (eventually) result in increasing the uncertainty of molal volumes of $\mathrm{Sr}^{2+}, \mathrm{NO}_{3}^{-}, \mathrm{F}^{-}$, and $\mathrm{Br}^{-}$ to as much as $\pm 3 \mathrm{~cm}^{3} \mathrm{~mol}^{-1}$ at $0^{\circ} \mathrm{C}$. Fortunately, these ions are typically minor contributors to the density of natural waters.
In order to determine the $\phi_{i}$ for ions, the additivity principle can be used, once a separation constant (or equivalently the value for one ion) is specified. All others can then be found by difference. A variety of conventions for this initial choice appear in the literature (Millero, 1972). As long as the chemical composition of an electrolyte is charge balanced, the choice makes no difference to the final sum as its effect on cations and anions cancels when summing over all ions.

To derive ionic apparent molal volumes here the following procedure is used. First, values for $\phi\left(\mathrm{Cl}^{-}\right)$are derived from $\phi(\mathrm{HCl})$ after specifying the volume of $\phi\left(\mathrm{H}^{+}\right)$. Then values for $\phi\left(\mathrm{Na}^{+}\right)$are derived from the difference between values for $\phi(\mathrm{NaCl})$ and $\phi\left(\mathrm{Cl}^{-}\right)$. Finally, values for all other cations are found from chloride salts, and for all other anions from sodium salts. 6 different cations and 9 different anions are modelled, deriving their values from the available data for 16 electrolytes.

The straightforward additivity assumptions implicit in Eq. (11) are not always valid. As concentrations increase, interactions between particular ions may become significant. Thus (11) will not correctly calculate $V_{\mathrm{I}}^{\prime}$. As an example, the apparent molal volume of $\mathrm{MgSO}_{4}$ is somewhat smaller than that computed from the sum of the volumes of the two constituent ions when they are derived from $\mathrm{Na}$ and $\mathrm{Cl}$ salts. More accurate calculations for multielectrolyte systems require consideration of these interactions.

Recent attempts at modelling seawater have relied on Pitzer equations (Monnin, 1994; Pierrot and Millero, 2000; Feistel and Marion, 2007) which systematically account for ionic interactions and are valid at high ionic strengths. However, such models do not provide more accurate results for seawater than the simpler Young's Rule approach (Pierrot and Millero, 2000), whose performance is well-known (Millero and Lepple, 1972; Millero, 2001). An advantage of the relative transparency of the Young's Rule approach is that it is straightforward to analytically evaluate the haline contraction coefficient. This allows us to investigate the importance of different ionic interactions. The Young's Rule approach also allows us to easily extend the range of compositions that can be modelled to include parameters for 20 different constituents, including 6 cations, 9 anions, and 5 nonconductive molecules.

In the Young's Rule approach specific cation/anion interactions in the $V_{\mathrm{I}}^{\prime}$ are included by computing the apparent molal volume as the sum of the $\phi_{j}$ for all $N^{+} \times N^{-}$binary electrolytes that can arise from combinations of the available cations and anions. The decomposition into binary electrolytes is done by assigning weights based on the relative amount of charge associated with the relevant cation/anion pair:

$V_{\mathrm{I}}^{\prime}=\sum_{j=1}^{N^{+} \times N^{-}} \frac{e_{j}^{\prime+} e_{j}^{\prime-}}{E^{\prime}} \phi_{j}^{*}$ 
The total equivalent concentration $E^{\prime}$ is the concentration of positive (or negative) charges:

$E^{\prime}=\sum_{i=1}^{N^{+}} z_{i}^{+} c_{i}^{\prime+}=\sum_{i=1}^{N^{-}} z_{i}^{-} c_{i}^{\prime-}=\frac{1}{2} \sum_{i=1}^{N} z_{i} c^{\prime}{ }_{i}$

with $e_{j}^{\prime+}=z_{j}^{+} c_{j}^{\prime+}$ and $e^{\prime-}=z_{j}^{-} c^{\prime}{ }_{j}^{-}$the total concentration of charges associated with the particular cation and anion that combines to form the $j$ th binary electrolyte. The $\phi_{j}^{*}$ are equivalent apparent molal volumes, equal to $\phi_{j}$ for $1: 1$ electrolytes, to $\phi_{j} / 2$ for 1:2 and 2:2 electrolytes, etc. Higherorder corrections to this Young's Rule decomposition arise as so-called excess mixing parameters, which will be assumed negligible in this development.

Some $N^{+} \times N^{-}=54$ binary electrolytes can be formed from the constituents considered here. However, data is available over all temperatures for only 12 , and at a single temperature $\left(25^{\circ} \mathrm{C}\right)$ for only a few more. No data is available for most of the 54 combinations. Although this is potentially a problem, significant pairing effects are known to arise only for some metal sulfates and metal carbonates (Pawlowicz, 2008). Additivity can therefore be used to estimate the apparent volume of most binary electrolytes from the apparent volumes of the constituent ions, which in turn are determined by difference from salts that do not exhibit pairing in the concentration range of interest. Only metal carbonates and metal sulfates must be handled separately.

Note that if additivity held for all electrolytes then Eq. (16) would be mathematically equivalent to the ion sum of Eq. (11). Intuitively this can be understood by recalling that additivity implies a particular anion would always be associated with the same apparent molal volume, no matter which cation it is being paired with in the decomposition to a set of binary electrolytes, and clearly the total mass of this anion must remain the same in either decomposition. The same will be true for the cations.

Among the metal carbonates and sulfates, reasonable measurements are available only for $\mathrm{MgSO}_{4}$. The effect of ion interactions leads to a difference between the molal volume for the electrolyte and for the sum of the ionic molal volumes estimated from sodium and chloride salts. That is, the difference

$\phi_{\text {pair }}=\phi\left(\mathrm{MgSO}_{4}\right)-\phi\left(\mathrm{Mg}^{2+}\right)-\phi\left(\mathrm{SO}_{4}^{2-}\right)$

is significantly nonzero at the concentrations of interest here. The interaction effect is estimated to be of similar strength for the other metal carbonates and sulfates. Thus for each of $M X$ where $M$ represents one of $\mathrm{Mg}^{2+}, \mathrm{Ca}^{2+}$, or $\mathrm{Sr}^{2+}$, and $X$ represents one of $\mathrm{SO}_{4}^{2-}$ or $\mathrm{CO}_{3}^{2-}$, we estimate

$\phi(M X)=\phi(M)+\phi(X)+\phi_{\text {pair }}$

with $\phi_{\text {pair }}$ defined using Eq. (18).

\subsection{Aqueous solution haline contraction coefficient}

The haline contraction coefficient $\beta$ measures the normalized effect on density of a perturbation in mass fraction salinity:

$\beta \equiv \frac{1}{\rho} \frac{\partial \rho}{\partial S}$

Although the simplest way of calculating $\beta$ is by direct numerical evaluation of the density change for a small perturbation $\delta S$ of whatever relative composition is desired, an analytical formulation can provide considerable insight. Consider a perturbation $\delta S^{\prime}$, composed of constituents $\delta c_{i}^{\prime}$, added to a fixed composition of salinity $S^{\prime}$ with constituent concentrations $c_{i}^{\prime}$. Then

$S^{\prime(2)}=S^{\prime}+\delta S^{\prime}=S^{\prime}+\sum M_{i} \delta c_{i}^{\prime}$

If $S^{\prime}$ changes then the apparent volume of solute will also change:

$V^{\prime(2)}=V^{\prime}+\delta V^{\prime} \approx V^{\prime}+\left.\sum \frac{\partial V^{\prime}}{\partial c_{i}^{\prime}}\right|_{T, c_{k \neq i}^{\prime}} \delta c_{i}^{\prime}=V^{\prime}+\sum \bar{V}_{i}^{\prime} \delta c_{i}^{\prime}$

The volume change involves partial molal volumes $\bar{V}_{i}^{\prime}=$ $\partial V^{\prime} / \partial c_{i}^{\prime}$ instead of the apparent volumes. The sum can be over ions as in Eq. (11) or (suitably modified into partial equivalent molal volumes) over all binary electrolytes using Young's Rule as in Eq. (16).

Now, the density $\rho^{(2)}$ of the modified fluid will be

$\rho^{(2)}=\rho_{0} \frac{1+S^{\prime(2)}}{1+\rho_{0} V^{\prime(2)}}$

and by subtracting Eq. (9) from (23) the density change $\delta \rho$ associated with $\delta S^{\prime}$ can be shown to be:

$\delta \rho \equiv \rho^{(2)}-\rho=\frac{\rho^{(2)} \delta S}{1-S}\left[1-\rho \frac{\delta V^{\prime}}{\delta S^{\prime}}\right]$

where the relationship $\delta S=(1-S-\delta S)(1-S) \delta S^{\prime}$ that follows from the definition (8) is required.

If we now assume that the perturbations have fixed relative composition $\Delta c_{i}^{\prime}$, multiplied by a scale factor $\xi$, i.e., $\delta c_{i}^{\prime}=$ $\xi \Delta c_{i}^{\prime}$, then

$\delta S^{\prime}=\sum M_{i} \xi \Delta c_{i}^{\prime} \equiv \xi \Delta S^{\prime}$
$\delta V^{\prime}=\sum \bar{V}_{i}^{\prime} \xi \Delta c_{i}^{\prime}$

By substituting into Eq. (24), rearranging, and taking the limit $\xi \rightarrow 0$ we can evaluate

$\beta=\lim _{\xi \rightarrow 0} \frac{\rho^{(2)}-\rho}{\rho^{(2)} \delta S}=\frac{1}{1-S}\left[1-\rho \frac{\sum \bar{V}_{i}^{\prime} \Delta c_{i}^{\prime}}{\sum M_{i} \Delta c_{i}^{\prime}}\right]$

The final result is not sensitive to $\xi$ at leading order, since it cancels from the numerator and denominator of the ratio term. 
The form of Eq. (27) is convenient for computing $\beta$, but for discussion purposes it is useful to rewrite this equation as

$\beta=\frac{1}{1-S} \sum\left(1-\frac{\rho \bar{V}_{i}^{\prime}}{M_{i}}\right) \frac{M_{i} \Delta c_{i}^{\prime}}{\Delta S^{\prime}}$

This shows that density changes arise when the density of the fluid differs from apparent densities $M_{i} / \bar{V}_{i}^{\prime}$ associated with the different constituents of the perturbation. The resulting anomalies are then weighted by relative mass fractions $M_{i} \Delta c_{i}^{\prime} / \Delta S^{\prime}$ of the constituents of the perturbation.

If we take the relative composition of the perturbation to be the same as the relative composition of the initial water, then Eq. (28) can be used to calculate the derivative of the salinity/density curve, $\rho \beta_{\mathrm{R}}$. Eq. (28) can also be used when the relative composition changes. The simplest case arises in laboratory experiments when salts are added. In this case many of the $\Delta c_{i}^{\prime}=0$, and the sum for $\beta$ is composed of only a few terms.

The relationship between perturbation concentrations on the two concentration scales is

$\xi \Delta c_{i}^{\prime}=\frac{\xi}{1-S-\xi \Delta S}\left[\Delta c_{i}+\Delta S \frac{c_{i}}{1-S}\right]$

which shows that the molonities of all constituents will typically change even if the molalities of most constituents do not (and vice versa). This occurs because molonities are diluted by the addition of any material, whereas molalities are only diluted by the addition of water. Substituting Eq. (29) into Eq. (28), $\beta$ can be rewritten exactly in terms of molonities:

$$
\begin{aligned}
& \beta=\sum\left(1-\frac{\rho \bar{V}_{i}^{\prime}}{M_{i}}\right) \frac{M_{i} \Delta c_{i}}{\Delta S}+\frac{S}{1-S} \sum\left(1-\frac{\rho \bar{V}_{i}^{\prime}}{M_{i}}\right) \frac{M_{i} c_{i}}{S} \\
& =\sum\left(1-\frac{\rho \bar{V}_{i}^{\prime}}{M_{i}}\right) \frac{M_{i} \Delta c_{i}}{\Delta S}+S \beta_{\mathrm{R}}
\end{aligned}
$$

The latter form is particularly useful, because in seawater problems molonity is the usual concentration scale.

It is of interest to consider an approximation to the true addition problem that uses the molonity scale. Instead of having a few nonzero $\Delta c^{\prime}{ }_{i}$, assume that modifications result in a few nonzero $\Delta \hat{c}_{i}=(1-S) \Delta c^{\prime}{ }_{i}$ (rather than using Eq. 29 to determine the true perturbation on the molonity scale). That is, ignore the dilution effect in determining the composition anomaly $\Delta \hat{c}_{i}$. This anomaly is numerically added to a fixed composition $C$ with salinity $S$, i.e. $S^{(2)}=S+\delta S$. The numerical difference between $\beta$ calculated using the original $\Delta c^{\prime}{ }_{i}$ and $\beta$ calculated using the approximations $\Delta \hat{c}_{i}$ is $\approx S\left(\beta-\beta_{\mathrm{R}}\right)$. If the relative composition of the perturbation matches that of seawater, so that $\beta=\beta_{\mathrm{R}}$, then both problems give the same numerical answer. In other situations considered in this paper the numerical difference is not larger than about $3 \%$ of the calculated value at most, and this is small enough to be ignored.
Finally, calculation of $\beta$ using Eqs. (27, 28 or 31) requires partial molal volumes $\bar{V}_{i}^{\prime}$. If the apparent volume of the solute is written as a sum of the apparent molal volumes of all ions:

$V^{\prime}=\sum_{j} \phi_{i}\left(I^{\prime}\right) c_{i}^{\prime}$

and since changes in $c_{i}^{\prime}$ will also affect $I^{\prime}$, then by using the chain rule

$$
\begin{aligned}
\delta V^{\prime} & =\xi \sum_{i} \bar{V}_{i}^{\prime} \Delta c_{i}^{\prime}=\xi \sum_{i} \frac{\partial V^{\prime}}{\partial c_{i}^{\prime}} \Delta c_{i}^{\prime} \\
& =\xi \sum_{i}\left(\phi_{i}+\sum_{j} \frac{d \phi_{j}}{d I^{\prime}} c_{j}^{\prime} \frac{z_{i}^{2}}{2}\right) \Delta c_{i}^{\prime} \\
& =\xi\left(\sum_{i} \phi_{i} \Delta c_{i}^{\prime}\right)+\xi\left(\sum_{i} \frac{d \phi_{i}}{d I^{\prime}} c_{i}^{\prime}\right) \cdot \Delta I^{\prime}
\end{aligned}
$$

where $\Delta I^{\prime}=\sum_{i} z_{i}^{2} \Delta c_{i}^{\prime} / 2$ is the perturbation in ionic strength. Partial molal volumes are then associated with a direct apparent volume change related to the addition of ions, as well as a large-scale change in the apparent volume of the ions already present, related to the increase in ionic strength.

The derivatives with respect to $I^{\prime}$ in the second term can be evaluated analytically from Eq. (14):

$$
\frac{d \phi_{j}}{d I^{\prime}}=\frac{1}{2 \sqrt{I^{\prime}}} A_{j}+B_{j}+\frac{3}{2} C_{j} \sqrt{I^{\prime}}+\ldots
$$

If we replace the ion sum in Eq. (32) with a Young's Rule decomposition over binary electrolytes (Eq. 16) then the intermediate term for partial molal volumes in the expansion (Eq. 34) is slightly different, but the final result (Eq. 35) is formally identical. However, adding a particular electrolyte will unavoidably change the weighting factors for all components, even in molal units, because these weighting factors are all coupled through $E^{\prime}$ :

$\Delta\left(\frac{e_{j}^{\prime+} e_{j}^{\prime-}}{E^{\prime}}\right)=\frac{\left(e_{j}^{\prime+}+\Delta e_{j}^{+}\right)\left(e^{\prime-}+\Delta e_{j}^{\prime-}\right)}{E^{\prime}+\Delta E^{\prime}}-\frac{e_{j}^{\prime+} e_{j}^{\prime}}{E^{\prime}}$

The resulting formula for $\beta$ is straightforward to compute, but tedious to manipulate analytically. A computer program LIMBETA has therefore been written implementing all of the procedures described.

\subsection{Seawater salinity and conductivity}

The density theory developed in the previous sections is general and can be applied to any natural water. In applications to seawater problems a number of additional factors must be considered. These factors, described in this Sect. and in Sects. 2.4 and 2.5 are implemented in a computer code LSEA_DELS, which makes use of LIMBETA as well as the composition/conductivity model LIMCOND of Pawlowicz (2008). 


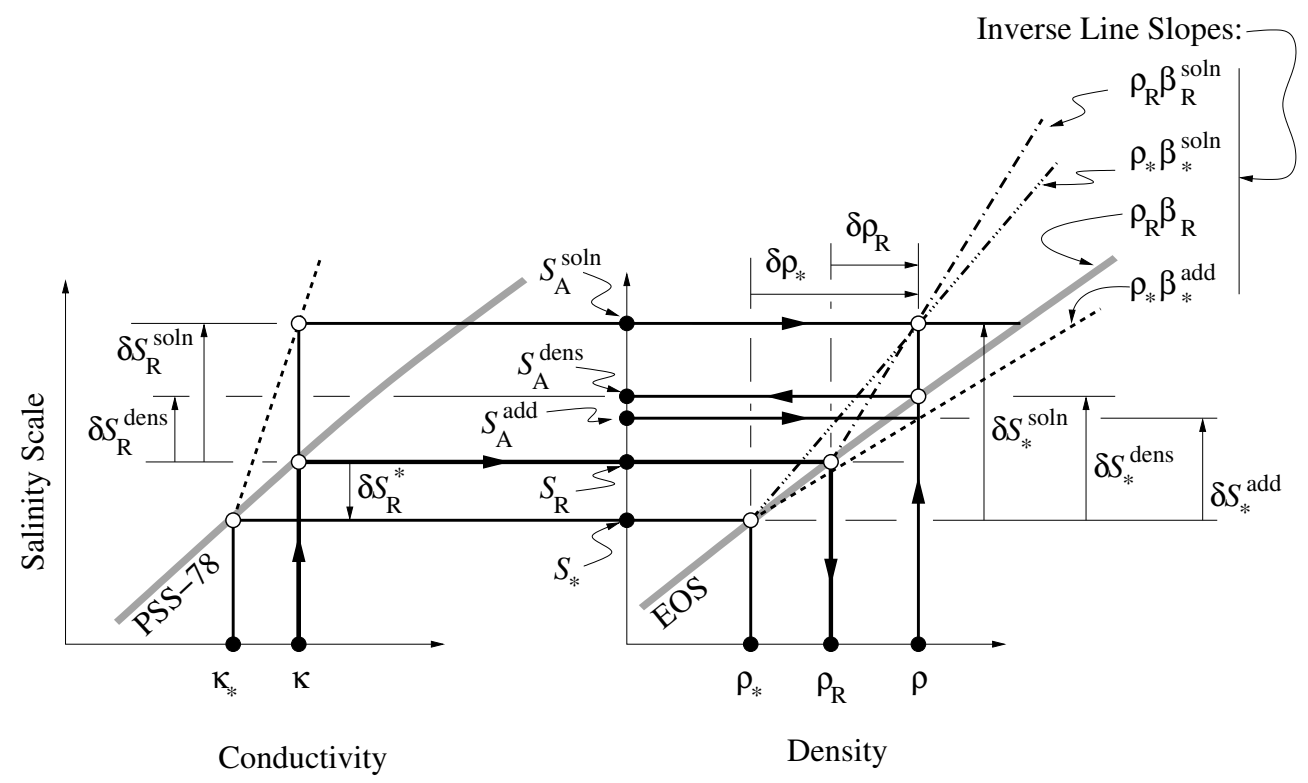

Fig. 1. Schematic illustrating the relationships between different salinities, densities, and conductivities used in the text. The conductivity/salinity relationship is on the left side with the scaled PSS-78 relationship shown as a gray curve. The density/salinity relationship on the right side, with the equation of state (EOS) for SSW shown as a gray curve. Salinity measures are common to both relationships. Salinities are indicated by subscripts for preformed $(*)$, reference $(\mathrm{R})$ and absolute (A) salinities, with further differentiations of the latter using superscripts for added salinity (add), density salinity (dens) and true or solution absolute salinity (soln). The notational convention for salinity variations is $S_{\text {to }}=S_{\text {from }}+\delta S_{\text {from }}^{\text {to }}$. For further information see Sect. 2.3 and Table 1 .

The simplest situation, which is relevant to laboratory studies and to ocean modelling applications, arises when a small amount of material is added to an existing seawater. This will be denoted the "constant chlorinity" case as the concentration of unreactive elements in seawater like $\mathrm{Cl}^{-}$ will remain unchanged with a biogeochemical perturbation.

However, when considering the density corrections to be applied to in situ ocean measurements, the perturbation will have to be constructed so that the conductivity of the initial and final compositions remains constant and fixed at the observed value. This will be denoted as the "constant conductivity" case. In order to understand the perturbations in these two situations, and their effects on the haline contraction coefficient, several different measures of salinity are involved (Fig. 1, Table 1).

First, consider a sample of IAPSO Standard Seawater. Its measured conductivity $\kappa_{*}$ can be related to a Practical Salinity $S_{\mathrm{P} *}$ using PSS-78, a SSW composition $C_{*}$, and the true absolute salinity $S_{*}=s\left(C_{*}\right) . S_{*}$ is, in turn, related to the true density $\rho_{*}$ by an equation of state for SSW.

Now, alter the concentrations of a small subset of the constituents of seawater to change the absolute salinity, i.e., let $C=C_{*}+\delta C_{*}$ for a known (small) perturbation $\delta C_{*}$ in which many elements $\delta c_{* i}$ may be zero. Concentrations of all ions for which $\delta c_{* i}$ are zero remain the same (hence constant chlorinity). This procedure approximately models a laboratory experiment in which a small mass of salt is added to seawater (see discussion after Eqs. 28 and 31).
The changed or anomalous seawater has a true conductivity $\kappa$ and true density $\rho$. Associated with $\kappa$ is a Practical Salinity $S_{\mathrm{P}}$, a notional reference composition $C_{\mathrm{R}}$ (the composition of Standard Seawater with the same $S_{\mathrm{P}}$ ), a reference salinity $S_{\mathrm{R}}=s\left(C_{\mathrm{R}}\right)$ using Eq. (2), and in turn a reference density $\rho_{\mathrm{R}}$, which is the density of SSW of the same $S_{\mathrm{P}}$. Associated with the true density $\rho$ is a density salinity $S_{\mathrm{A}}^{\text {dens }}$, determined purely by inversion of the SSW density/salinity relationship. In addition, the density anomaly from the reference, $\delta \rho_{\mathrm{R}}$, is defined by

$\delta \rho_{\mathrm{R}} \equiv \rho-\rho_{\mathrm{R}}$

and a true density anomaly from the original water, $\delta \rho_{*}$, is defined by

$\delta \rho_{*} \equiv \rho-\rho_{*}$

The salinity anomaly $\delta S_{\mathrm{R}}^{\text {soln }}$ from the reference value can be calculated from full knowledge of $C_{\mathrm{R}}$ and the true composition $C$ :

$$
\begin{aligned}
\delta S_{\mathrm{R}}^{\text {soln }} & \equiv S_{\mathrm{A}}^{\text {soln }}-S_{\mathrm{R}}=s(C)-s\left(C_{\mathrm{R}}\right) \\
& =s\left(\delta C_{\mathrm{R}}\right)=\sum_{i=1}^{N_{c}} M_{i} \delta c_{\mathrm{R} i}
\end{aligned}
$$


Table 1. Glossary of important symbols and abbreviations.

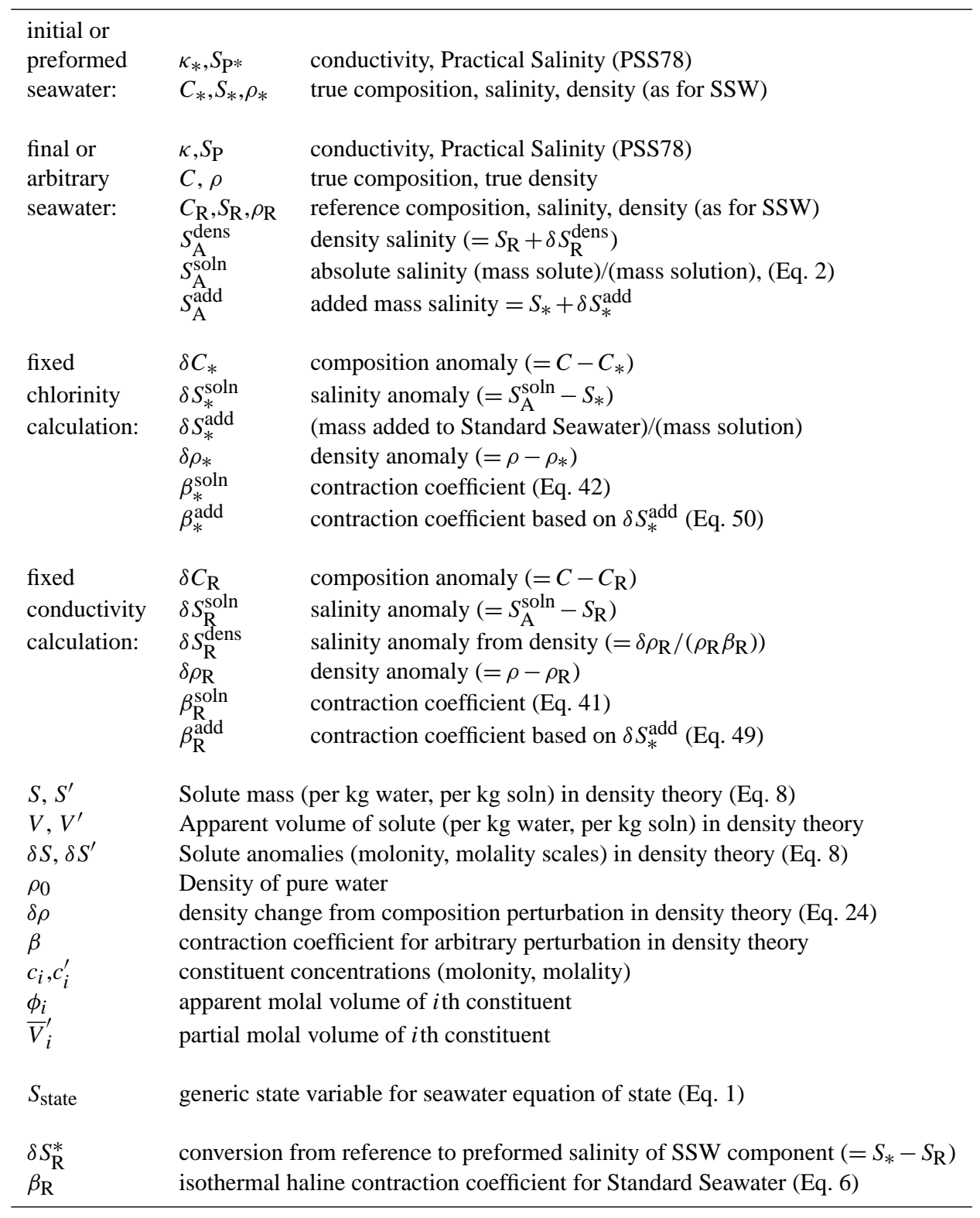

but the true change in the absolute salinity from the original water is

$$
\begin{aligned}
\delta S_{*}^{\text {soln }} & \equiv S_{\mathrm{A}}^{\text {soln }}-S_{*}=s(C)-s\left(C_{*}\right) \\
& =s\left(\delta C_{*}\right)=\sum_{i=1}^{N_{c}} M_{i} \delta c_{* i}
\end{aligned}
$$

Note that $\delta S_{*}^{\text {soln }}$ may not necessarily be equivalent to the actual amount of mass added relative to the mass of the seawater sample, denoted $\delta S_{*}^{\text {add }}$. This is because of chemical reactions that may take place within the water, in which $\mathrm{H}_{2} \mathrm{O}$ may dissociate into $\mathrm{H}^{+}$and $\mathrm{OH}^{-}$components which then combine with the elements being dissolved. This will occur, for example, in additions involving carbonate species.

If the material added is not very conductive, as is the case for biogeochemical anomalies (Pawlowicz, 2010), then the conductivity will not change as much as it would for additions of sea salt, and the point $\left(\kappa, S_{\mathrm{A}}^{\mathrm{soln}}\right)$ will lie above the PSS-78 curve, as indicated by the dashed line on the left side of Fig. 1. This curve diverges from the PSS-78 relationship at $\kappa_{*}$, and can be determined from a full conductivity model. In addition, if the added material increases the solution volume more than the change that would occur for the same mass of sea salt, then the point $\left(\rho, S_{\mathrm{A}}^{\mathrm{soln}}\right)$ will also lie above the curve 
Table 2. Parameters from Eq. (14) for apparent molal volumes $\left(\mathrm{cm}^{3} \mathrm{~mol}^{-1}\right)$ of binary electrolytes for temperatures $0{ }^{\circ} \mathrm{C}$ to $50^{\circ} \mathrm{C}$. These equations are in terms of molalities $c_{j}^{\prime}=I^{\prime} / w_{j}$. Sources are: $\mathrm{NaCl}, \mathrm{Na}_{2} \mathrm{SO}_{4}, \mathrm{MgCl}_{2}, \mathrm{MgSO}_{4}-$ Lo Surdo et al. (1982), $\mathrm{NaHCO}_{3}$ and $\mathrm{Na}_{2} \mathrm{CO}_{3}$ - Hershey et al. (1983), $\mathrm{NaB}(\mathrm{OH})_{4}, \mathrm{~B}(\mathrm{OH})_{3}$ - Ward and Millero (1974), $\mathrm{KCl}, \mathrm{CaCl}_{2}$ - equations fit to model output of Mao and Duan (2008), $\mathrm{HCl}, \mathrm{NaOH}$ - Millero et al. (1972), with $\mathrm{HCl}$ refitted to raw data.

\begin{tabular}{lrrrrrr}
\hline- & $\mathrm{NaCl}$ & $\mathrm{Na}_{2} \mathrm{SO}_{4}$ & $\mathrm{MgCl}_{2}$ & $\mathrm{MgSO}_{4}$ & $\mathrm{NaHCO}_{3}$ & $\mathrm{Na}_{2} \mathrm{CO}_{3}$ \\
$w_{j}$ & 1 & 3 & 3 & 4 & 1 & 3 \\
\hline$v_{j 0}$ & 12.870 & 2.126 & 10.336 & -13.278 & 17.4977 & -15.5645 \\
$v_{j 0}^{(1)}$ & 0.2423 & 0.5384 & 0.2983 & 0.3522 & $3.41347 \mathrm{e}-1$ & $5.9354 \mathrm{e}-1$ \\
$v_{j 0}^{(2)}$ & $-4.4741 \mathrm{e}-3$ & $-6.4051 \mathrm{e}-3$ & $-6.8778 \mathrm{e}-3$ & $-4.3372 \mathrm{e}-3$ & $-4.3601 \mathrm{e}-3$ & $-1.2112 \mathrm{e}-2$ \\
$v_{j 0}^{(3)}$ & $3.1601 \mathrm{e}-5$ & $8.8200 \mathrm{e}-6$ & $4.1345 \mathrm{e}-5$ & $-1.3013 \mathrm{e}-5$ & $3.3604 \mathrm{e}-7$ & $1.1032 \mathrm{e}-4$ \\
$A_{j}^{(0)}$ & 1.8055 & 8.4742 & 9.7046 & 36.3245 & 1.98209 & 9.45551 \\
$A_{j}^{(1)}$ & $-1.7967 \mathrm{e}-2$ & 0.1271 & -0.1150 & -0.2575 & $3.34829 \mathrm{e}-2$ & -0.263456 \\
$A_{j}^{(2)}$ & $5.5444 \mathrm{e}-4$ & $-1.3701 \mathrm{e}-3$ & $2.4866 \mathrm{e}-3$ & $8.8526 \mathrm{e}-3$ & $-3.63868 \mathrm{e}-3$ & $1.31314 \mathrm{e}-2$ \\
$A_{j}^{(3)}$ & 0 & 0 & 0 & 0 & $8.92557 \mathrm{e}-5$ & $-1.60376 \mathrm{e}-4$ \\
$B_{j}^{(0)}$ & 0.8999 & 17.3342 & -4.9657 & -57.8034 & 6.64518 & 8.73920 \\
$B_{j}^{(1)}$ & $-2.6792 \mathrm{e}-2$ & -0.9333 & $1.5080 \mathrm{e}-2$ & -0.1183 & $-7.1967 \mathrm{e}-2$ & -0.118837 \\
$B_{j}^{(2)}$ & $1.4929 \mathrm{e}-5$ & $1.2049 \mathrm{e}-2$ & $-7.6301 \mathrm{e}-4$ & $-9.7965 \mathrm{e}-3$ & 0 & 0 \\
$B_{j}^{(3)}$ & 0 & 0 & 0 & 0 & 0 & 0 \\
$C_{j}^{(0)}$ & -0.1985 & -9.7022 & 3.3785 & 74.0708 & -3.64246 & -2.62316 \\
$C_{j}^{(1)}$ & $5.5640 \mathrm{e}-3$ & 0.5567 & $7.9003 \mathrm{e}-5$ & 0.2752 & 0 & 0 \\
$C_{j}^{(2)}$ & 0 & $-7.6066 \mathrm{e}-3$ & $1.0568 \mathrm{e}-4$ & $5.4991 \mathrm{e}-3$ & 0 & 0 \\
$C_{j}^{(3)}$ & 0 & 0 & 0 & 0 & 0 & 0 \\
$D_{j}^{(0)}$ & 0 & 0 & -0.7703 & 46.8604 & 0 & 0 \\
$D_{j}^{(1)}$ & 0 & 0 & 0 & -0.1075 & 0 & 0 \\
$D_{j}^{(2)}$ & 0 & 0 & 0 & $-0.1605 \mathrm{e}-3$ & 0 & 0 \\
$D_{j}^{(3)}$ & 0 & 0 & 0 & 0 & 0 & 0 \\
$E_{j}^{(0)}$ & 0 & 0 & 0 & 11.3688 & 0 & 0 \\
\hline & & & & & & 0 \\
\hline
\end{tabular}

representing the SSW equation of state, along another curve, diverging from the SSW curve at $\rho_{*}$, as indicated on the right side of Fig. 1.

For small perturbations the slopes of the different curves are approximately constant. Then two different haline contraction coefficients can be defined:

$\left.\beta_{\mathrm{R}}^{\text {soln }} \equiv \frac{1}{\rho_{\mathrm{R}}} \sum_{i=1}^{N_{c}} \frac{\partial \rho}{\partial\left(M_{i} c_{i}\right)}\right|_{\rho_{\mathrm{R}}} \frac{M_{i} \delta c_{\mathrm{R} i}}{\delta S_{\mathrm{R}}^{\text {soln }}} \approx \frac{1}{\rho_{\mathrm{R}}} \frac{\delta \rho_{\mathrm{R}}}{\delta S_{\mathrm{R}}^{\text {soln }}}$

relating the absolute to the reference salinity, both corresponding to the same sample of anomalous seawater, and

$\left.\beta_{*}^{\text {soln }} \equiv \frac{1}{\rho_{*}} \sum_{i=1}^{N_{c}} \frac{\partial \rho}{\partial\left(M_{i} c_{i}\right)}\right|_{\rho_{*}} \frac{M_{i} \delta c_{* i}}{\delta S_{*}^{\text {soln }}} \approx \frac{1}{\rho_{*}} \frac{\delta \rho_{*}}{\delta S_{*}^{\text {soln }}}$

relating the absolute salinities of the seawater before and after the addition of anomalous material.

The haline contraction coefficients $\beta_{\mathrm{R}}^{\text {soln }}$ and $\beta_{*}^{\text {soln }}$ depend on properties of seawater, as well as the details of the relative composition of the pertubation, but can be computed from Eqs. $(27,28$, or 31$)$ once $\delta C_{\mathrm{R}}$ or $\delta C_{*}$ are known. The partial derivative terms in Eqs. (41 and 42) are the properties of seawater. For small perturbations these are not sensitive to the numerical differences between $\rho_{\mathrm{R}}, \rho_{*}$, and $\rho$. By comparison with Eqs. $(27,28$, or 31) these partial derivatives are clearly proportional to terms of the form $1-\rho \bar{V}_{i}^{\prime} / M_{i}$; the dependence on the composition arises in the calculation of partial molal volumes $\bar{V}_{i}^{\prime}$.

The constant conductivity case, which will be used to model ocean observations, can be understood with the same schematic, but with a different starting point. In this case the measured conductivity $\kappa$ of the modified seawater is known (from which $S_{\mathrm{R}}$ and $\rho_{\mathrm{R}}$ are calculated assuming that this $\kappa$ measured a SSW). A measurement of the true density $\rho$, or equivalently a measurement of $\delta \rho_{\mathrm{R}}$, can be inverted into an estimate of $\delta S_{\mathrm{R}}^{\text {dens }}$ and hence $S_{\mathrm{A}}^{\text {dens }}$ using $\beta_{\mathrm{R}}$. If, however, $S_{\mathrm{A}}^{\text {soln }}$ is desired, then knowledge of $S_{*}$ is required. This is 
Table 3. Parameters from Eq. (14) continued.

\begin{tabular}{lrrrrrr}
\hline- & $\mathrm{NaB}(\mathrm{OH})_{4}$ & $\mathrm{~B}(\mathrm{OH})_{3}$ & $\mathrm{KCl}$ & $\mathrm{CaCl}_{2}$ & $\mathrm{HCl}$ & $\mathrm{NaOH}$ \\
$w_{j}$ & 1 & 1 & 1 & 3 & 1 & 1 \\
\hline$v_{j 0}$ & 12.38 & 36.56 & 23.35 & 13.40 & 16.37 & -11.20 \\
$v_{j 0}^{(1)}$ & 0.434 & 0.13 & 0.2587 & 0.2800 & 0.0896 & 0.35040 \\
$v_{j 0}^{(2)}$ & $-4.229 \mathrm{e}-3$ & $-8.1 \mathrm{e}-4$ & $-5.1734 \mathrm{e}-3$ & $-5.7918 \mathrm{e}-3$ & $-1.264 \mathrm{e}-3$ & $-4.4160 \mathrm{e}-3$ \\
$v_{j 0}^{(3)}$ & 0 & 0 & $3.8487 \mathrm{e}-5$ & $4.1403 \mathrm{e}-5$ & 0 & 0 \\
$A_{j}^{(0)}$ & 1.4447 & 0 & 1.4783 & 6.6367 & 1.3997 & 4.2380 \\
$A_{j}^{(1)}$ & $1.6799 \mathrm{e}-2$ & 0 & $1.00834 \mathrm{e}-2$ & $5.3689 \mathrm{e}-2$ & $1.636 \mathrm{e}-3$ & -0.15290 \\
$A_{j}^{(2)}$ & $-8.4055 \mathrm{e}-6$ & 0 & $8.6654 \mathrm{e}-5$ & $3.2431 \mathrm{e}-4$ & $4.8464 \mathrm{e}-4$ & $2.3400 \mathrm{e}-3$ \\
$A_{j}^{(3)}$ & $5.55153 \mathrm{e}-7$ & 0 & 0 & 0 & 0 & 0 \\
$B_{j}^{(0)}$ & 8.856 & 0.09 & 0.64507 & -0.12690 & -1.9368 & 4.9080 \\
$B_{j}^{(1)}$ & -0.235 & $4.0 \mathrm{e}-4$ & $-3.5860 \mathrm{e}-2$ & $-8.2642 \mathrm{e}-2$ & $3.65992 \mathrm{e}-2$ & -0.25402 \\
$B_{j}^{(2)}$ & $2.794 \mathrm{e}-3$ & 0 & $4.262 \mathrm{e}-4$ & $6.2636 \mathrm{e}-4$ & $5.9591 \mathrm{e}-5$ & $3.8296 \mathrm{e}-3$ \\
$B_{j}^{(3)}$ & 0 & 0 & 0 & 0 & 0 & 0 \\
$C_{j}^{(0)}$ & 0 & 0 & 0 & 0 & 2.2967 & -3.3920 \\
$C_{j}^{(1)}$ & 0 & 0 & 0 & 0 & $-3.0578 \mathrm{e}-2$ & 0.22504 \\
$C_{j}^{(2)}$ & 0 & 0 & 0 & 0 & $-1.57886 \mathrm{e}-3$ & $-3.1968 \mathrm{e}-3$ \\
$C_{j}^{(3)}$ & 0 & 0 & 0 & 0 & 0 & 0 \\
$D_{j}^{(0)}$ & 0 & 0 & 0 & 0 & -0.8724 & 0 \\
$D_{j}^{(1)}$ & 0 & 0 & 0 & 0 & $-1.8990 \mathrm{e}-3$ & $7.36 \mathrm{e}-3$ \\
$D_{j}^{(2)}$ & 0 & 0 & 0 & 0 & $1.20628 \mathrm{e}-3$ & $-2.944 \mathrm{e}-4$ \\
$D_{j}^{(3)}$ & 0 & 0 & 0 & 0 & 0 & 0 \\
$E_{j}^{(0)}$ & 0 & 0 & 0 & 0 & 0 & 0 \\
\hline & & & & & & \\
\hline
\end{tabular}

because the true composition $C$ is not a straightforward modification of $C_{\mathrm{R}}$. Instead, it is most easily found as a modification of $C_{*}$.

The composition $C_{*}$ will be a dilution of $C_{\mathrm{R}}$, i.e. $C_{*}=$ $\alpha C_{\mathrm{R}}$, for some as-yet undetermined constant $\alpha$. To this diluted water is added $\delta C_{*}$, with whatever nutrients and carbonate parameters are required to match ocean observations. Effectively a composition $C=\alpha C_{\mathrm{R}}+\delta C_{*}$ must be constructed in which observed parameters like $\mathrm{NO}_{3}^{-}$are fixed at their observed levels, but all unobserved parameters are set to $\alpha c_{i}$. The reason for this dilution is that the addition of ionic nutrients that can increase conductivity must be matched by a decrease of (other) ions, to keep conductivity constant, under the constraint that the relative composition of the unreactive constituents of seawater remains the same. In order to find the dilution factor $\alpha$ a nonlinear conductivity equation:

$\kappa\left(\alpha C_{\mathrm{R}}+\delta C_{*}\right)=\kappa\left(C_{\mathrm{R}}\right)$

must be solved. This can be done iteratively using the seawater conductivity model described in Pawlowicz (2010). Note that the right hand side is not necessarily the measured con- ductivity, but rather the conductivity at reference temperature and pressure.

The notional dilution implies that the concentration of every unobserved constituent, relative to that found in the composition of Standard Seawater appropriate for the measured $S_{\mathrm{P}}$, will change (albeit by a small amount). The dilution itself is of interest, because this water has precisely the composition of Standard Seawater. The salinity $S_{*}$ of this water, which in this context can be called a preformed seawater, then characterizes the part of seawater unaffected by biogeochemical processes. $S_{*}$ will be conservative in the sense that it is set by boundary processes, but affected only by advection and diffusion within the ocean. In the following discussion we will also refer to the anomaly $\delta S_{\mathrm{R}}^{*}$ defined by

$S_{*} \equiv S_{\mathrm{R}}+\delta S_{\mathrm{R}}^{*}$

or $\delta S_{\mathrm{R}}^{*}=(\alpha-1) S_{\mathrm{R}}$.

The values of $\beta_{\mathrm{R}}^{\text {soln }}$ and $\beta_{*}^{\text {soln }}$ are influenced by different choices of the base state and the perturbations with respect to those states, and hence are generally numerically different. With the aid of Fig. 1 it can be shown that the $\delta \rho_{\mathrm{R}} / \delta S_{\mathrm{A}}^{\text {soln }}$ 
Table 4. Parameters from Eq. (14) for apparent molal volumes $\left(\mathrm{cm}^{3} \mathrm{~mol}^{-1}\right)$ of binary electrolytes at $25^{\circ} \mathrm{C}$. These equations are in terms of ionic stength $I^{\prime}$. Sources are $\mathrm{NaF}, \mathrm{NaNO}_{3}, \mathrm{NaBr}, \mathrm{SrCl}_{2}-$ Millero et al. (1977), $\mathrm{Si}(\mathrm{OH})_{4}-$ Duedall et al. $(1976), \mathrm{CO}_{2}, \mathrm{O}_{2}, \mathrm{~N}_{2}-\mathrm{Watanabe}$ and Iizuka (1985).

\begin{tabular}{lrrrrrrrr}
\hline- & $\mathrm{NaF}$ & $\mathrm{NaNO}_{3}$ & $\mathrm{NaBr}$ & $\mathrm{SrCl}_{2}$ & $\mathrm{Si}(\mathrm{OH})_{4}$ & $\mathrm{CO}_{2}$ & $\mathrm{O}_{2}$ & $\mathrm{~N}_{2}$ \\
\hline$v_{j 0}$ & -2.371 & 27.805 & 23.504 & 17.975 & 60 & 35.698 & 30.553 & 34.54 \\
$A_{j}^{(0)}$ & 1.839 & 2.586 & 1.689 & 3.941 & 0 & 0 & 0 & 0 \\
$B_{j}^{(0)}$ & 0.561 & -0.292 & 0.076 & -0.038 & 0 & 0 & 0 & 0 \\
\hline
\end{tabular}

relationship can be re-written in terms of $\beta_{*}^{\text {soln }}$ as follows:

$$
\begin{aligned}
\delta \rho_{\mathrm{R}} & =\rho_{\mathrm{R}} \beta_{\mathrm{R}}^{\text {soln }} \delta S_{\mathrm{R}}^{\text {soln }} \\
& =\rho_{*} \beta_{*}^{\text {soln }} \delta S_{\mathrm{R}}^{\text {soln }}+\left(\rho_{\mathrm{R}} \beta_{\mathrm{R}}-\rho_{*} \beta_{*}^{\text {soln }}\right) \delta S_{\mathrm{R}}^{*}
\end{aligned}
$$

If the effects of added material on conductivity and density differ from that of added sea salt, then $\beta_{*}^{\text {soln }}$ and $\beta_{\mathrm{R}}$ will differ. The magnitude of the conductivity effect will then govern the difference between $\beta_{\mathrm{R}}^{\text {soln }}$ and $\beta_{*}^{\text {soln }}$. When material added to $C_{*}$ is conductive, $\delta S_{\mathrm{R}}^{*}$ will be large and hence $\beta_{\mathrm{R}}^{\text {soln }}$ and $\beta_{*}^{\text {soln }}$ will differ. $\beta_{\mathrm{R}}^{\text {soln }}$ and $\beta_{*}^{\text {soln }}$ agree only in the case when the perturbed composition is completely nonionic, e.g., the addition of only $\mathrm{Si}(\mathrm{OH})_{4}$.

The widespread concentration changes in fixed conductivity calculations make analysis of the results considerably more complex, without necessarily adding any insight. In the following numerical examples where complete compositions are discussed only composition changes for the constant chlorinity case are shown, but both $\beta_{*}^{\text {soln }}$ and $\beta_{\mathrm{R}}^{\text {soln }}$ are computed. $\beta_{\mathrm{R}}^{\text {soln }}$ will also be used to correct hydrographic profile data.

\subsection{Standard Seawater Composition}

In order to carry out calculations using the theory developed above, a chemical model of seawater is required, specifying concentrations of the different constituents over a range of salinities. The SSW76 model for seawater (Pawlowicz, 2010), containing all inorganic constituents affecting salinity at amounts of $\geq 1 \mathrm{mg} \mathrm{kg}^{-1}$ is used. Although not a full chemical model, which is beyond the scope of this work, SSW76 can account for variations in salinity, as well as compositional changes arising from changing chemical equilibria in the carbonate subsystem. It is therefore an extension of the fixed Reference Composition (RC) of Millero et al. (2008a).

The seawater carbonate system in SSW76 is described using well known nonlinear equilibrium dynamics (Dickson et al., 2007). The system is characterized by the Total Alkalinity TA:

$\mathrm{TA} \equiv\left[\mathrm{HCO}_{3}^{-}\right]+2\left[\mathrm{CO}_{3}^{2-}\right]+\left[\mathrm{B}(\mathrm{OH})_{4}^{-}\right]+\left[\mathrm{OH}^{-}\right]-\left[\mathrm{H}^{+}\right]$

and dissolved inorganic carbon (DIC):

$\mathrm{DIC} \equiv\left[\mathrm{CO}_{2}\right]+\left[\mathrm{HCO}_{3}^{-}\right]+\left[\mathrm{CO}_{3}^{2-}\right]$ with [.] representing concentrations (molonity). Minor dependences arise from the total amount of $\mathrm{B}$ as $\mathrm{B}(\mathrm{OH})_{4}^{-}$and $\mathrm{B}(\mathrm{OH})_{3}, \mathrm{SO}_{4}^{2-}$, and a number of other constituents whose concentrations are well below our threshold of $1 \mathrm{mg} \mathrm{kg}^{-1}$ (Millero, 1995). TA and DIC are routinely measured conservative parameters. Their values in SSW76 are $2300 \times$ $\left(S_{\mathrm{P}} / 35\right) \mu \mathrm{mol} \mathrm{kg} \mathrm{kg}^{-1}$ and $2080 \times\left(S_{\mathrm{P}} / 35\right) \mu \mathrm{mol} \mathrm{kg}{ }^{-1}$ respectively. The individual components of TA and DIC, and related parameters such as the $\mathrm{pH}$, are computed using equilibrium constants that, in turn, vary with temperature, pressure, and the overall salinity or ionic strength (Dickson et al., 2007).

Although the concentration of TA in SSW76 follows the choice made in the definition of the Reference Composition (Millero et al., 2008a), DIC levels are about $117 \mu \mathrm{mol} \mathrm{kg}^{-1}$ higher. A comprehensive discussion of the factors involved in this choice is given in Pawlowicz (2010). Briefly, a number of factors suggest that the actual value in 1970s vintage Standard Seawater and/or in North Atlantic surface water may be anywhere from 0 to $240 \mu \mathrm{mol} \mathrm{kg}^{-1}$ higher than the RC value, but with considerable uncertainty. However, within that range, the SSW76 choice results in $\delta S_{\mathrm{R}}^{\text {soln }} \approx 0$ for real cases when $\delta \rho_{\mathrm{R}} \approx 0$.

Numerical parameters for SSW76 at $S_{\mathrm{P}}=35$ and $t=25^{\circ} \mathrm{C}$ are shown in Table 5, column 2. The composition of Standard Seawater at other salinities is approximately obtained by scaling these concentrations (Pawlowicz, 2010). Note that absolute salinity of this model SSW ("model $S_{\mathrm{R}}$ ") calculated using Eq. (2) is $\left(35.17124 / 35 \times S_{\mathrm{P}}\right) \mathrm{g} \mathrm{kg}^{-1}$. This is slightly larger than the $S_{\mathrm{R}}$ that would be obtained via Eq. (3) for water of the same $S_{\mathrm{P}}$ using the TEOS-10 scale factor $u_{\mathrm{PS}}=35.16504 / 35$ ("TEOS-10 $S_{\mathrm{R}}$ "). This is because the DIC content of SSW76 is slightly larger than the DIC content of the Reference Composition.

We are primarily concerned in this paper with relationships between anomalies in conductivity, salinity, and density, arising from composition anomalies that modify SSW. These are insensitive to the "base" salinity value, although not always to the concentrations of individual constituents in SSW. The application of our results to ocean analyses in which salinities are measured on the Reference Composition Scale of TEOS-10 will be discussed later. However, it must 
Table 5. Haline contraction coefficients for various combinations of biogeochemical processes. The first column is the composition of Standard Seawater (SSW76) with $S_{\mathrm{P}}=35$, after Pawlowicz (2010), as well as the calculated $\beta_{\mathrm{R}}^{\text {soln }}=\beta_{*}^{\text {soln }}=\beta_{\mathrm{R}}$ at temperatures of $25^{\circ} \mathrm{C}$ and $1^{\circ} \mathrm{C}$. Subsequent columns provide $\delta c_{* i}, \delta S_{*}^{\text {soln }}$ and $S_{\mathrm{R}}^{\text {soln }}$ for different additions and combinations of additions, as well as $\beta_{\mathrm{R}}^{\text {soln }}$ and $\beta_{*}^{\text {soln }}$. All concentrations are in $\mathrm{mg} \mathrm{kg}^{-1}$. Perturbations of zero are denoted “-”. Perturbations denoted " 0.00 ” are nonzero, but too small to affect salinity.

\begin{tabular}{|c|c|c|c|c|c|c|c|c|c|c|}
\hline & SSW76 & All & noSi & noNO3 & noDIC & noTA & $\mathrm{Si}$ & NO3 & DIC & TA \\
\hline $\mathrm{Na}$ & 10781.35913 & - & - & - & - & - & - & - & - & - \\
\hline $\mathrm{Mg}$ & 1283.71757 & - & - & - & - & - & - & - & - & - \\
\hline $\mathrm{Ca}$ & 412.08380 & 3.81 & 3.81 & 3.01 & 3.81 & 0.80 & - & 0.80 & - & 3.01 \\
\hline $\mathrm{K}$ & 399.10324 & - & - & - & - & - & - & - & - & - \\
\hline $\mathrm{Sr}$ & 7.94332 & - & - & - & - & - & - & - & - & - \\
\hline $\mathrm{Cl}$ & 19352.71293 & - & - & - & - & - & - & - & - & - \\
\hline $\mathrm{SO}_{4}$ & 2712.35228 & - & - & - & - & - & - & - & - & - \\
\hline $\mathrm{Br}$ & 67.28578 & - & - & - & - & - & - & - & - & - \\
\hline $\mathrm{F}$ & 1.29805 & - & - & - & - & - & - & - & - & - \\
\hline $\mathrm{HCO}_{3}^{-}$ & 115.94926 & 21.39 & 21.39 & 21.39 & -5.78 & 19.85 & - & - & 19.85 & -5.78 \\
\hline $\mathrm{CO}_{3}^{2-}$ & 9.77242 & -4.84 & -4.84 & -4.84 & 6.14 & -7.95 & - & - & -7.95 & 6.14 \\
\hline $\mathrm{B}(\mathrm{OH})_{3}$ & 21.38143 & 2.26 & 2.26 & 2.26 & -2.27 & 3.49 & - & - & 3.49 & -2.27 \\
\hline $\mathrm{B}(\mathrm{OH})_{4}^{-}$ & 5.45779 & -2.89 & -2.89 & -2.89 & 2.90 & -4.45 & - & - & -4.45 & 2.90 \\
\hline $\mathrm{CO}_{2}$ & 0.74233 & 1.32 & 1.32 & 1.32 & -0.33 & 4.71 & - & - & 4.71 & -0.33 \\
\hline $\mathrm{OH}^{-}$ & 0.08172 & -0.05 & -0.05 & -0.05 & 0.06 & -0.07 & - & - & -0.07 & 0.06 \\
\hline $\mathrm{H}^{+}$ & 0.00001 & 0.00 & 0.00 & 0.00 & -0.00 & 0.00 & - & - & 0.00 & -0.00 \\
\hline $\mathrm{NO}_{3}^{-}$ & 0.00000 & 2.48 & 2.48 & - & 2.48 & 2.48 & - & 2.48 & - & - \\
\hline $\mathrm{Si}(\mathrm{OH})_{4}$ & 0.00000 & 16.34 & - & 16.34 & 16.34 & 16.34 & 16.34 & - & - & - \\
\hline $\mathrm{pH}_{\text {Total }}$ & 7.89892 & -0.37 & -0.37 & -0.37 & 0.23 & -0.80 & - & - & -0.80 & 0.23 \\
\hline$S_{\mathrm{A}}^{\text {soln }}, \delta S_{*}^{\text {soln }}$ & 35171.241 & 39.834 & 23.494 & 36.552 & 23.336 & 35.212 & 16.340 & 3.282 & 15.590 & 3.714 \\
\hline$\delta S_{*}^{\mathrm{R}}$ & & 6.206 & 6.206 & 4.577 & 4.095 & 3.237 & - & 1.629 & 1.608 & 2.466 \\
\hline$\beta_{*}^{\text {soln }}$ & 0.735 & 0.489 & 0.559 & 0.467 & 0.722 & 0.322 & 0.387 & 0.735 & 0.166 & 2.185 \\
\hline $\begin{array}{l}\beta_{\mathrm{R}}^{\text {soln }} \\
\mathrm{t}=1^{\circ} \mathrm{C}\end{array}$ & 0.735 & 0.439 & 0.490 & 0.425 & 0.719 & 0.276 & 0.387 & 0.735 & 0.095 & 5.763 \\
\hline$\beta_{*}^{\text {soln }}$ & 0.779 & 0.519 & 0.588 & 0.498 & 0.761 & 0.353 & 0.421 & 0.758 & 0.197 & 2.255 \\
\hline$\beta_{\mathrm{R}}^{\text {soln }}$ & 0.779 & 0.460 & 0.500 & 0.447 & 0.758 & 0.296 & 0.421 & 0.732 & 0.094 & 4.897 \\
\hline
\end{tabular}

be emphasized that when a numerical argument is required for the TEOS-10 equation of state, which occurs only during model validation, it is taken to be "TEOS-10 $S_{\mathrm{R}}$ ", i.e. $u_{\mathrm{PS}} S_{\mathrm{P}}$.

\subsection{Composition anomalies}

Analyses of seawater from different oceans suggest that composition changes greater than a threshold of $1 \mathrm{mg} \mathrm{kg}^{-1}$ arise primarily from the addition of nutrients $\mathrm{NO}_{3}^{-}$and $\mathrm{Si}(\mathrm{OH})_{4}$, and changes in the carbonate system via changes in TA and DIC (Brewer and Bradshaw, 1975; Pawlowicz, 2010). Numerical values for these parameters, which are a standard part of modern hydrographic programs, will then be taken as inputs to the calculations.

However, we cannot just add ions to the base composition in a chemical model. Increases in $\mathrm{TA}$ and $\mathrm{NO}_{3}^{-}$require a counterbalancing increase in one or more positive ions (or a decrease in some other negative ion) to preserve charge bal- ance. The dissolution of $\mathrm{CaCO}_{3}$ is assumed to be the most important counterbalancing source in the open ocean, leading to another constraint in the model:

$$
\Delta \mathrm{TA}+\Delta\left[\mathrm{NO}_{3}^{-}\right]=2 \Delta\left[\mathrm{Ca}^{2+}\right]
$$

where $\Delta$ represents the changes from values in SSW76. $\mathrm{Ca}^{2+}$ is not routinely measured. Changes in its concentration will therefore be inferred from Eq. (48) in order to maintain charge balance.

Actual ocean observations of $\mathrm{Ca}^{2+}$ variations differ slightly from the values estimated by Eq. (48), but the excess values are of order $0.8 \mathrm{mg} \mathrm{kg}^{-1}$, which is (barely) under our threshold (de Villiers, 1998). In some situations increases in TA may be balanced in other ways. In coastal areas reductions in $\mathrm{SO}_{4}^{-}$may be important (Pavlova et al., 2008; Chen, 2002). Surface increases in the Arctic are complex, and greatly affected by freshwater inflows (Bates and Mathis, 

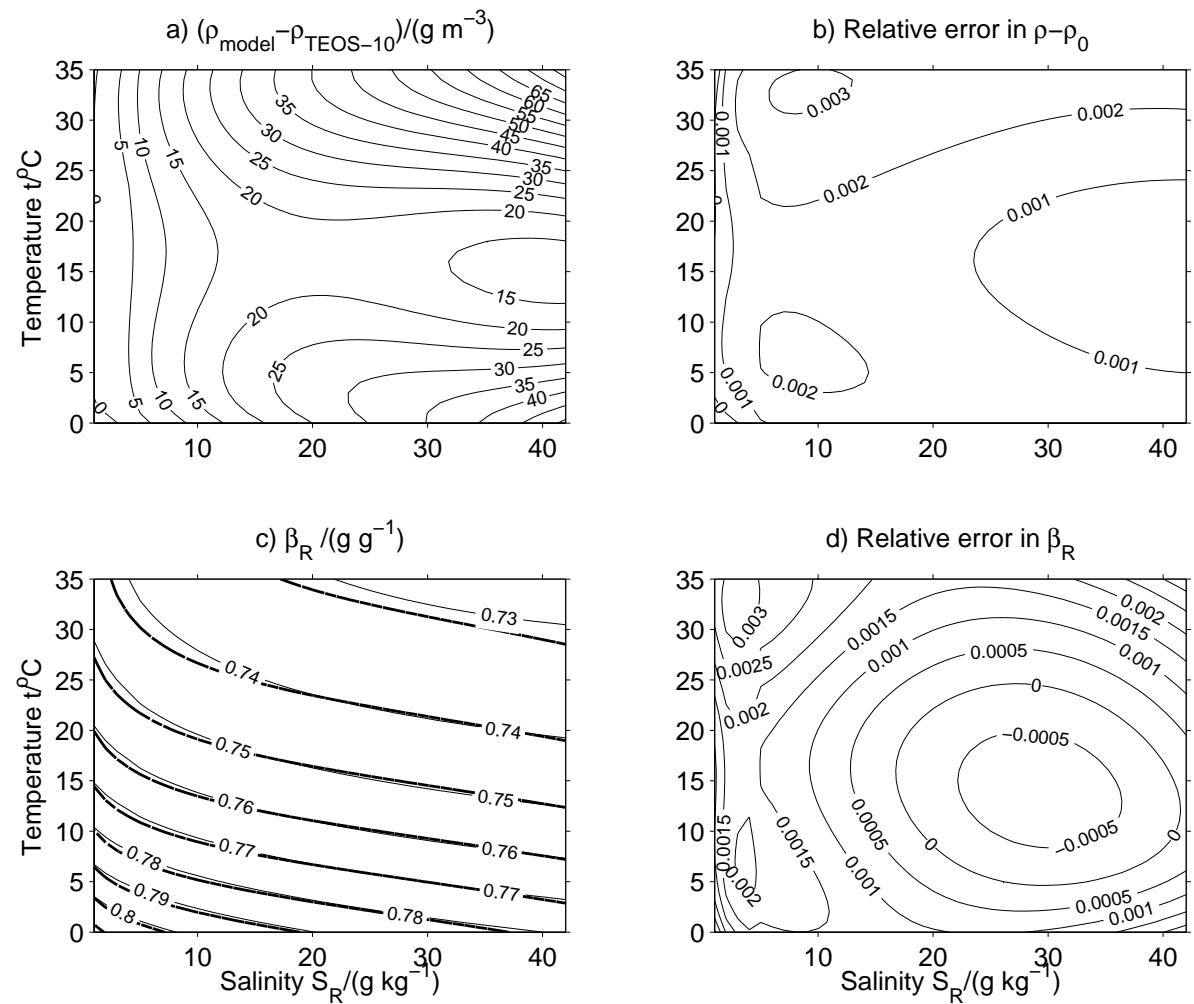

Fig. 2. Comparison between TEOS-10 and LIMBETA densities and haline contraction coefficient, over the general range of seawater (a) Differences in predicted densities. (b) Relative error in density anomaly from pure water values. (c) $\beta_{\mathrm{R}}$ for model (thick dashed lines) and from TEOS-10 (thin lines). (d) Relative error in model $\beta_{\mathrm{R}}$.

2009). Detailed analysis of conductivity/salinity/density relations in these situations will be considered elsewhere.

\section{Results}

\subsection{Validation for $\rho$ and $\beta_{\mathrm{R}}$ calculations}

LIMBETA was used to calculate densities over the range $0^{\circ} \mathrm{C} \leq t \leq 35^{\circ} \mathrm{C}$ and $0 \mathrm{~g} \mathrm{~kg}^{-1} \leq S_{\mathrm{R}} \leq 42 \mathrm{~g} \mathrm{~kg}^{-1}$ for the SSW76 model of Standard Seawater. These densities were compared with those obtained from the TEOS-10 equation of state (Feistel, 2008), whose accuracy is considered to be better than $4 \mathrm{~g} \mathrm{~m}^{-3}$ over this range of temperature and salinity. LIMBETA systematically overpredicts density with an RMS error of $22 \mathrm{~g} \mathrm{~m}^{-3}$ over this temperature/salinity range, with greater errors at high and low temperatures when salinities are highest (Fig. 2a). The relative error in the anomaly from the density of pure water at the same temperature, i.e., $\rho(S, t)-\rho_{0}(t)$, which is the density change actually modelled, is only about 0.002 (Fig. 2b). This is similar to the relative uncertainty of the measurements of the molal volumes of binary electrolytes on which the model is based.
The haline contraction coefficient $\beta_{\mathrm{R}}$ calculated using Eq. (27) can also be compared to that provided by TEOS10 (Fig. 2c). When relative error is contoured over the whole range, largest systematic differences can be seen at low salinities and at high temperatures (Fig. 2d), but these are no larger than 0.003 . The RMS difference over the temperatures $0^{\circ} \mathrm{C}$ to $25^{\circ} \mathrm{C}$ and salinities $5 \mathrm{~g} \mathrm{~kg}^{-1}$ to $40 \mathrm{~g} \mathrm{~kg}^{-1}$ is $6 \times 10^{-4} \mathrm{~g} \mathrm{~g}^{-1}$.

Model performance degrades slowly at even higher salinities. Recently, measurements were made of seawater density at salinities of up to $70 \mathrm{~g} \mathrm{~kg}^{-1}$ (Millero and Huang, 2009). A polynomial fit with an RMS error of $3.6 \mathrm{~g} \mathrm{~m}^{-3}$ is provided over temperatures of $0^{\circ} \mathrm{C}$ to $40^{\circ} \mathrm{C}$ (Millero and Huang, 2009, Table 3). Directly comparing both the ion sum and the Young's Rule calculation with that polynomial (Fig. 3a) shows that our model overestimates density at low salinities, but that this error decreases and changes sign at high salinities. Also, the ion-ion interactions parameterized in the Young's Rule calculation for binary electrolytes make little difference at low salinities, but decrease calculated densities by $30 \mathrm{~g} \mathrm{~m}^{-3}$ at highest salinities. Model agreement with the measurements at high salinities is better than that of TEOS10. The DES2010 correction to TEOS-10 (Feistel, 2010), 

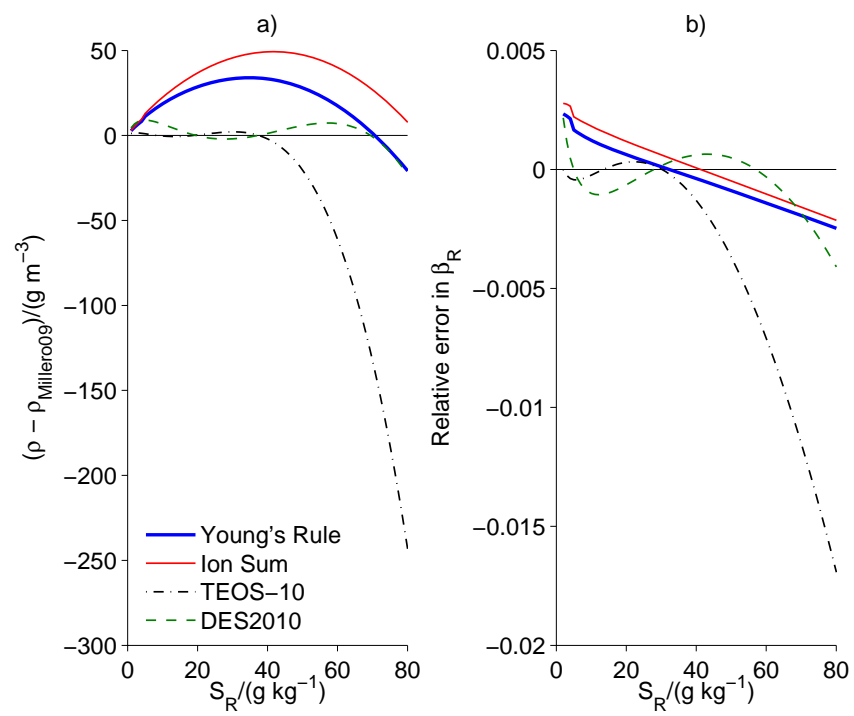

Fig. 3. Comparison between (a) model densities and (b) haline contraction coefficient $\beta_{\mathrm{R}}$ determined from the model, and those obtained by direct measurements (Millero and Huang, 2009), for salinities up to $80 \mathrm{~g} \mathrm{~kg}^{-1}$ at $t=25^{\circ} \mathrm{C}$.

which incorporates these new measurements, lies close to the LIMBETA results at high salinities. In the mid-range of salinities, the DES2010 result is closer to the measurements although the differences show several oscillations over the full range of salinity which apparently arise from some inconsistencies in the database of high-salinity measurements (R. Feistel, personal communication, 2009).

Comparisons of model $\beta_{\mathrm{R}}$ and that directly calculated using Eq. (6) and the density equation of Millero and Huang (2009) over the same range of salinity (Fig. 3b) show good agreement. Again, at high salinities the model predictions appear to match observations better than those of TEOS-10, and are reasonably similar to DES2010. In addition, the relatively small change between the ion sum and Young's Rule calculation suggests that accounting for ion-ion interactions in the more complex Young's Rule approach provides very little advantage over the simple ion sum, at least in this case. The good agreement between LIMBETA calculations, whose algorithm is in no way tuned to seawater densities, and the purely empirical fits to measured densities, suggests that there is no inherent drawback to using the Young's Rule approach instead of the more formally correct Pitzer approach in this application. Over $0{ }^{\circ} \mathrm{C} \leq t \leq 25^{\circ} \mathrm{C}$ and $5 \mathrm{~g} \mathrm{~kg}^{-1} \leq S_{\mathrm{R}} \leq 40 \mathrm{~g} \mathrm{~kg}^{-1}$, the performance of LIMBETA compares favourably with a recent Pitzer model of seawater, which has larger RMS errors of $60 \mathrm{~g} \mathrm{~m}^{-3}$ in density and $3 \times 10^{-3} \mathrm{~g} \mathrm{~g}^{-1}$ in $\beta$ (Feistel and Marion, 2007).
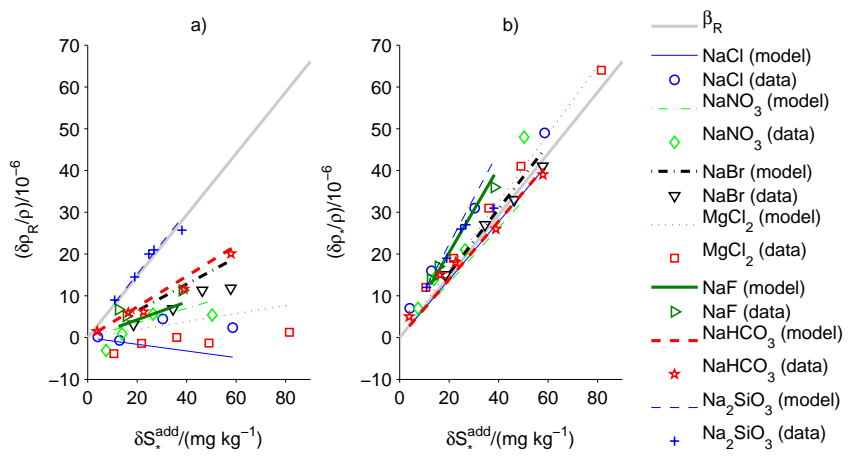

Fig. 4. Laboratory measurements (data) and model predictions (model) for relationships between added mass $\delta S_{*}^{\text {add }}$ and density anomalies (a) $\delta \rho_{\mathrm{R}} / \rho$ and (b) $\delta \rho_{*} / \rho$ for different added salts. Thick gray line shows slope $\beta_{\mathrm{R}}$.

\subsection{Laboratory manipulations of Standard Seawater}

Laboratory experiments were carried out in which known amounts $\delta S_{*}^{\text {add }}$ of different salts were added to Standard Seawater to produce a mixture (Table 6, Fig. 4). Both $\delta \rho_{\mathrm{R}}$ and $\delta \rho_{*}$ can be directly calculated from measurements of the conductivity and density of both the original and mixed waters. These values can also be calculated from LSEA_DELS using the measured conductivity and specified compositional perturbation. In these cases, the true nature of the perturbations are known, so Eq. (48) is not required.

The mean difference between predicted and measured $\delta \rho_{\mathrm{R}}$ for all the different salts considered is $(-1.26 \pm 3.58) \mathrm{g} \mathrm{m}^{-3}$ (Table 6). This agreement is entirely consistent with the uncertainty of the conductivity and density measurements. However, the obvious definition for a useful contraction coefficient, relating the added mass and the measured density anomaly

$\beta_{\mathrm{R}}^{\text {add }} \equiv \frac{1}{\rho_{\mathrm{R}}} \frac{\delta \rho_{\mathrm{R}}}{\delta S_{*}^{\text {add }}}$

varies tremendously (Fig. 4a), even changing sign for some salts, and is clearly not well approximated by $\beta_{\mathrm{R}}$ in general.

A large part of this discrepancy arises from the sensitivity of solution conductivity to the composition of the perturbation. We can eliminate this issue by using the true density increase $\delta \rho_{*}$, which is possible in both laboratory experiments and in our numerical calculations. Model predictions for $\delta \rho_{*}$ are again in good agreement with the measurements, slightly larger by $(0.82 \pm 4.94) \mathrm{g} \mathrm{m}^{-3}$. Correlation with $\delta S_{*}^{\text {add }}$ (Fig. 4 b) is much better. Although the values of

$\beta_{*}^{\text {add }} \equiv \frac{1}{\rho_{*}} \frac{\delta \rho_{*}}{\delta S_{*}^{\text {add }}}$

range from $0.67 \mathrm{~g} \mathrm{~g}^{-1}$ to $1.14 \mathrm{~g} \mathrm{~g}^{-1}$ for different salts the root-mean-square error that arises from using $\beta_{\mathrm{R}}=$ 
Table 6. Density and conductivity changes resulting from laboratory additions of various salts to IAPSO Standard Seawater (batch P152). All measurements at $t=25.000^{\circ} \mathrm{C}$.

\begin{tabular}{|c|c|c|c|c|c|c|}
\hline $\begin{array}{l}S_{\mathrm{P}^{*}} \\
\text { original }\end{array}$ & $\begin{array}{r}S_{\mathrm{P}} \\
\text { mixture }\end{array}$ & $\begin{array}{r}\delta S_{*}^{\text {add }} \\
\mathrm{mg} \mathrm{kg}^{-1}\end{array}$ & $\begin{array}{r}\delta \rho_{\mathrm{R}} \\
\text { (measured) } \\
\mathrm{g} \mathrm{m}^{-3}\end{array}$ & $\begin{array}{r}\delta \rho_{\mathrm{R}} \\
\text { (model) } \\
\mathrm{g} \mathrm{m}^{-3}\end{array}$ & $\begin{array}{l}\text { Diff. } \\
\mathrm{g} \mathrm{m}^{-3}\end{array}$ & $\begin{array}{r}\delta S_{*}^{\text {soln }}-\delta S_{*}^{\text {add }} \\
\mathrm{mg} \mathrm{kg}^{-1}\end{array}$ \\
\hline & & $\mathrm{NaCl}$ & & & & \\
\hline 36.319 & 36.328 & 4.07 & 0.17 & -0.32 & -0.49 & - \\
\hline 36.319 & 36.341 & 12.90 & -0.66 & -1.03 & -0.37 & - \\
\hline 36.319 & 36.354 & 30.30 & 4.50 & -2.41 & -6.91 & - \\
\hline 36.312 & 36.374 & 58.60 & 2.38 & -4.67 & -7.05 & - \\
\hline & & $\mathrm{NaNO}_{3}$ & & & & \\
\hline 36.313 & 36.327 & 7.47 & -3.07 & 1.31 & 4.38 & - \\
\hline 36.313 & 36.331 & 13.90 & 0.90 & 2.44 & 1.54 & - \\
\hline 36.313 & 36.334 & 26.40 & 5.63 & 4.63 & -1.00 & - \\
\hline 36.313 & 36.370 & 50.30 & 5.40 & 8.82 & 3.42 & - \\
\hline & & $\mathrm{NaBr}$ & & & & \\
\hline 36.312 & 36.328 & 18.50 & 3.17 & 5.91 & 2.74 & - \\
\hline 36.312 & 36.339 & 34.50 & 6.85 & 11.02 & 4.17 & - \\
\hline 36.312 & 36.341 & 46.30 & 11.30 & 14.79 & 3.49 & - \\
\hline 36.312 & 36.351 & 57.80 & 11.80 & 18.46 & 6.66 & - \\
\hline & & $\mathrm{MgCl}_{2}$ & & & & \\
\hline 35.461 & 35.483 & 10.60 & -3.85 & 1.02 & 4.87 & - \\
\hline 35.461 & 35.489 & 21.80 & -1.38 & 2.09 & 3.47 & - \\
\hline 35.461 & 35.503 & 36.00 & 0.03 & 3.45 & 3.42 & - \\
\hline 35.461 & 35.518 & 49.00 & -1.31 & 4.70 & 6.01 & - \\
\hline 35.461 & 35.545 & 81.50 & 1.28 & 7.82 & 6.54 & - \\
\hline & & $\mathrm{NaF}$ & & & & \\
\hline 36.312 & 36.322 & 12.50 & 6.71 & 2.67 & -4.04 & - \\
\hline 36.312 & 36.328 & 15.70 & 5.17 & 3.35 & -1.82 & - \\
\hline 36.312 & 36.345 & 38.30 & 11.30 & 8.18 & -3.12 & - \\
\hline & & $\mathrm{NaHCO}_{3}$ & & & & \\
\hline 35.463 & 35.468 & 3.90 & 1.49 & 1.43 & -0.06 & -0.03 \\
\hline 36.315 & 36.327 & 16.40 & 5.93 & 6.03 & 0.10 & -0.11 \\
\hline 35.464 & 35.479 & 22.60 & 6.18 & 8.30 & 2.12 & -0.15 \\
\hline 36.315 & 36.334 & 38.90 & 11.60 & 14.31 & 2.71 & -0.26 \\
\hline 36.315 & 36.340 & 57.90 & 20.10 & 21.29 & 1.19 & -0.38 \\
\hline & & $\mathrm{Na}_{2} \mathrm{SiO}_{3}$ & & & & \\
\hline 36.314 & 36.319 & 10.90 & 8.98 & 8.31 & -0.67 & 2.61 \\
\hline 36.314 & 36.321 & 19.00 & 14.50 & 14.45 & -0.05 & 4.46 \\
\hline 36.314 & 36.323 & 24.70 & 20.00 & 18.73 & -1.27 & 5.74 \\
\hline 36.314 & 36.323 & 26.80 & 21.00 & 20.30 & -0.70 & 6.20 \\
\hline 36.314 & 36.322 & 38.10 & 25.70 & 28.68 & 2.98 & 8.67 \\
\hline \multicolumn{7}{|c|}{$-1.26 \pm 3.58$} \\
\hline
\end{tabular}

$0.735 \mathrm{~g} \mathrm{~g}^{-1}$ to describe the density change is only $\pm 5.1 \mathrm{~g} \mathrm{~m}^{-3}$ over all salts considered. This is reasonably close to the measurement accuracy, although will clearly underestimate the density change for several salts.

In order to understand the contribution of specific salts to the contraction coefficient it is useful to examine the weights $\left(1-\rho \bar{V}_{i}^{\prime} / M_{i}\right)$ which play a central role in Eqs. (28 and 31), and hence in Eq. (41) (Fig. 5). Since ionic apparent volumes are specified only up to an arbitrary separation constant the resulting values are not unique, even though the apparent volumes of charge-balanced electrolytes are well-defined. However, this freedom can be exploited. As seawater is primarily composed of $\mathrm{NaCl}$ it is convenient to choose the separation constant so that the apparent molal densities $M_{i} / \phi_{i}$ of 


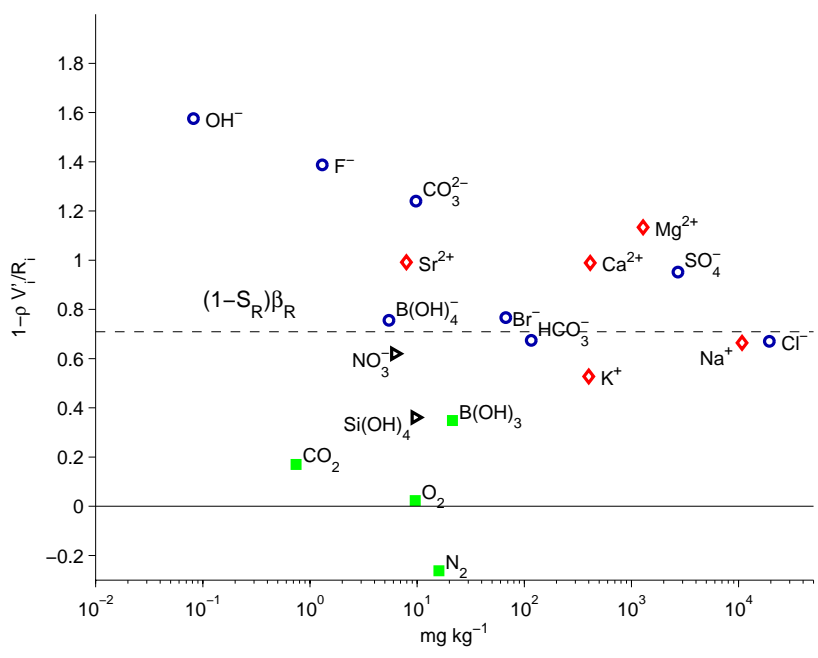

Fig. 5. Weighting terms $1-\rho \bar{V}_{i}^{\prime} / M_{i}$ in Eq. (28) for seawater at $25^{\circ} \mathrm{C}$. Coordinates along X-axis give masses $M_{i} c_{i}$ in seawater with $S_{\mathrm{P}}=35$. Horizontal dashed line shows calculated $\left(1-S_{\mathrm{R}}\right) \beta_{\mathrm{R}}$ for seawater.

$\mathrm{Na}$ and $\mathrm{Cl}$ are the same. Changing the separation constant will move all negative ions in one direction in Fig. 5, say upwards, with lighter ions moving slightly further than heavier ions, while moving all positive ions in the opposite direction (downwards). However, the mass-weighted average location of the charge-balanced sum of a positive and a negative ion will remain unchanged. The location of neutral constituents will not be affected by changes in the separation constant. From the figure, it can be seen that $\beta_{\mathrm{R}}$ is primarily determined by $\mathrm{NaCl}$ which dominates the composition, but is increased slightly by the presence of $\mathrm{MgSO}_{4}$, and then affected in smaller measure by the remaining constituents.

Some salts, such as $\mathrm{NaCl}, \mathrm{NaBr}$ and $\mathrm{NaNO}_{3}$ have apparent densities very similar to that of seasalt so that $\beta_{*}^{\text {soln }} \approx \beta_{\mathrm{R}}$ when these are added. However, this in no way implies that $\beta_{\mathrm{R}}^{\text {soln }} \approx \beta_{\mathrm{R}}$, which requires additional constraints related to effects on conductivity. Salts such as $\mathrm{MgCl}_{2}$ and $\mathrm{NaF}$ have weight terms somewhat larger than $\beta_{\mathrm{R}}$. Addition of these salts to seawater causes density changes greater than would be predicted if a similar mass of sea salt was added.

Although not investigated here, neutral constituents such as $\mathrm{Si}(\mathrm{OH})_{4}$ and $\mathrm{B}(\mathrm{OH})_{3}$ are relatively light for the volume occupied in solution (or equivalently relatively bulky for their mass), and will cause much smaller density changes than would occur from the addition of a similar mass of sea salt. Changes in the dissolved gas $\mathrm{O}_{2}$ will cause virtually no change, as its apparent density is almost identical to that of water. Slightly more noticeable changes in density could occur through variations in $\mathrm{N}_{2}$ and $\mathrm{CO}_{2}$. However, oceanic variations in $\mathrm{N}_{2}$ are quite small, as are overall concentrations of $\mathrm{CO}_{2}$, so in practise their neglect in density modelling is reasonable.
Analysis for additions of salts like $\mathrm{NaHCO}_{3}$ and $\mathrm{Na}_{2} \mathrm{SiO}_{3}$ is potentially complex because of chemical reactions that occur after addition. In order to model these additions it is easier to deal with quantities that will not be altered by the reactions. The addition of $\mathrm{NaHCO}_{3}$ obviously results in an increase in the concentration of $\mathrm{Na}^{+}$as the salt dissolves. In contrast, the equal amount of $\mathrm{HCO}_{3}^{-}$added will not remain in this form. However, the increase in both the inorganic carbon content (measured by the change in DIC), and in the negative charge required to counterbalance the increase in positive charge from the $\mathrm{Na}^{+}$(measured by a change in TA) are not affected by transformations within the carbonate system. Thus we model the addition of $\mathrm{NaHCO}_{3}$ as being an addition of exactly equal amounts of $\mathrm{Na}^{+}$, DIC, and TA. The actual changes in the final concentrations of all components of the carbonate system are then solved from the equilibrium equations, as described in Sect. 2.4.

In this particular case, the equilibrium state of seawater is such that the equilibrium reactions have little effect, and the composition changes that occur in the carbonate system are by far the largest for $\mathrm{HCO}_{3}^{-}$alone. The difference between $\delta S_{*}^{\text {soln }}$ (the calculated change in absolute salinity after equilibrium is reached) and $\delta S_{*}^{\text {add }}$ (the actual amount of added mass) is not zero, but is reasonably small (Table 6, last column). Finally, the apparent density of the combination of $\mathrm{Na}^{+}$and $\mathrm{HCO}_{3}^{-}$is not too different from that of sea salt (Fig. 5).

The addition of $\mathrm{Na}_{2} \mathrm{SiO}_{3}$ also results in an increase in $\mathrm{Na}^{+}$. However, most of the $\mathrm{SiO}_{3}^{2-}$ will undergo hydrolysis at the $\mathrm{pH}$ of seawater and will appear as $\mathrm{Si}(\mathrm{OH})_{4}$ (Duedall et al., 1976). Charge balance is maintained by an increase in TA. Thus reactions involving $\mathrm{SiO}_{3}^{2-}$ result in $\delta S_{*}^{\text {soln }}$ being about 1.23 times larger than $\delta S_{*}^{\text {add }}$ (Table 6). Effects of increases in the TA of seawater, without a change in DIC, mostly involve the conversion of $\mathrm{HCO}_{3}^{-}$into $\mathrm{CO}_{3}^{2-}$, but also involve the conversion of $\mathrm{B}(\mathrm{OH})_{3}$ into $\mathrm{B}(\mathrm{OH})_{4}^{-}$, as will be shown more clearly in the next section.

In all cases model predictions are in good agreement with the laboratory results. Furthermore, in most cases these results can be quickly explained in terms of the known characteristics of the different ions involved. However, the sensitivity of these results to the relative composition of the perturbation, especially in the fixed conductivity calculations, and the potential difficulties in dealing with changes in the carbonate system, implies that the actual compositional anomalies that arise from specific biogeochemical processes in the ocean must be examined, and that conductivity effects should also be considered.

\subsection{North Pacific intermediate water}

Largest changes in the composition of seawater relative to the reference state occur at intermediate depths in the North Pacific. Based on typical observations we consider a model North Pacific seawater with $S_{\mathrm{P}}=35$ to have 
$\mathrm{Si}(\mathrm{OH})_{4}=170 \mu \mathrm{mol} \mathrm{kg}-1$ and $\mathrm{NO}_{3}^{-}=40 \mu \mathrm{mol} \mathrm{kg}{ }^{-1}$, with TA and DIC larger than SSW76 values by $150 \mu \mathrm{mol} \mathrm{kg}^{-1}$ and $300 \mu \mathrm{mol} \mathrm{kg}{ }^{-1}$ respectively. By inference through Eq. (48)

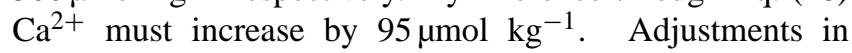
the carbonate system are again determined as discussed in Sect. 2.4.

In this case (Table 5, column "All”), the computed $\beta_{\mathrm{R}}^{\text {soln }} \approx$ $\beta_{*}^{\text {soln }} \approx 0.45 \mathrm{~g} \mathrm{~g}^{-1}$, about two thirds of $\beta_{\mathrm{R}}=0.735 \mathrm{~g} \mathrm{~g}^{-1}$ (both at $25^{\circ} \mathrm{C}$ ), and the difference between $\beta_{*}^{\text {soln }}$ and $\beta_{\mathrm{R}}^{\text {soln }}$ is about $11 \%$. Largest changes in mass occur for $\mathrm{HCO}_{3}^{-}$and $\mathrm{Si}(\mathrm{OH})_{4}$, but changes in $\mathrm{pH}$ also occur, and these are related to smaller changes within the whole carbonate system.

Although all calculations are performed at $25^{\circ} \mathrm{C}$, appropriate for laboratory measurements, the effects of temperature dependence on the contraction coefficients is relatively small. At $1^{\circ} \mathrm{C} \beta_{\mathrm{R}}=0.779 \mathrm{~g} \mathrm{~g}^{-1}$ and $\beta_{\mathrm{R}}^{\text {soln }} \approx \beta_{*}^{\text {soln }} \approx 0.48 \mathrm{~g} \mathrm{~g}^{-1}$. The increases of 0.044 and $0.03 \mathrm{~g} \mathrm{~g}^{-1}$, respectively, over the values at $25^{\circ} \mathrm{C}$ are relatively small compared to the differences between $\beta_{\mathrm{R}}$ and $\beta_{\mathrm{R}}^{\text {soln }}$.

To study the sensitivity of the calculated contraction coefficients to different components of the perturbation, 4 cases are considered in which each of the 4 observational parameters is set to zero in turn while leaving the others unchanged as inputs to the model (Columns 4-7 of Table 5). At $25^{\circ} \mathrm{C}$ the fixed conductivity $\beta_{\mathrm{R}}^{\text {soln }}$ increases slightly to $0.490 \mathrm{~g} \mathrm{~g}^{-1}$ without the addition of $\mathrm{Si}(\mathrm{OH})_{4}$ (case "noSi"), and decreases slightly to $0.425 \mathrm{~g} \mathrm{~g}^{-1}$ without added $\mathrm{NO}_{3}^{-}$("noNO3"). If

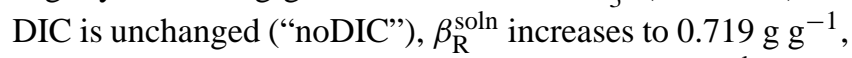
approaching $\beta_{\mathrm{R}}$, but if TA is set to zero ("noTA") $\beta_{\mathrm{R}}^{\text {soln }}$ drops to $0.276 \mathrm{~g} \mathrm{~g}^{-1}$. Values at $1^{\circ} \mathrm{C}$ are slightly greater, but the difference is at most $0.04 \mathrm{~g} \mathrm{~g}^{-1}$.

In spite of this sensitivity to composition, $\beta_{\mathrm{R}}^{\text {soln }} \approx \beta_{*}^{\text {soln }}$ in almost all cases, and is at all times less than $\beta_{\mathrm{R}}$. In all cases except where $\triangle \mathrm{DIC}$ is set to zero the changes in the carbonate system dominate the contributions to the changes in $S_{\mathrm{A}}^{\text {soln }}$. Consequently, nutrients cannot be considered the most important influence on these contraction coefficients, even though the mass change from $\mathrm{Si}(\mathrm{OH})_{4}$ is relatively large. Note that only about $10-20 \%$ of the total salinity change $\delta S_{*}^{\text {soln }}$ is accounted for by changes in conductivity-based reference salinity, i.e. in $\delta S_{\mathrm{R}}^{\text {soln }}$.

In a second set of cases, all parameters are set to zero except one (Columns $8-11$ of Table 5). The variation in calculated $\beta_{\mathrm{R}}^{\text {soln }}$ is larger, from a minimum of $0.095 \mathrm{~g} \mathrm{~g}^{-1}$ when DIC alone is added ("DIC"), to a value nearly identical to $\beta_{\mathrm{R}}$ when $\mathrm{Ca}\left(\mathrm{NO}_{3}\right)_{2}$ is added ("NO3"), to a rather large $5.763 \mathrm{~g} \mathrm{~g}^{-1}$ in the last case ("TA") which models the somewhat unrealistic case of $\mathrm{CaCO}_{3}$ dissolution without an increase in DIC. The large change here occurs because relatively light $\mathrm{B}(\mathrm{OH})_{3}$ and $\mathrm{HCO}_{3}^{-}$are removed, and replaced with relatively dense $\mathrm{B}(\mathrm{OH})_{4}^{-}$and $\mathrm{CO}_{3}^{2-}$.

The difference between $\beta_{*}^{\text {soln }}$ and $\beta_{\mathrm{R}}^{\text {soln }}$ ranges from zero for an addition of $\mathrm{Si}(\mathrm{OH})_{4}$ or $\mathrm{NO}_{3}^{-}$, indicating that nutrient additions in themselves do not greatly affect conductivity, to almost 4 for case "TA". Changes in the carbonate system may have a large effect on conductivity and density anomalies, but the form of the change is important. DIC variations alone have little effect on density, whereas the effect of TA changes can be large.

Although concentrations of $\mathrm{Si}(\mathrm{OH})_{4}$ increase in seawater due to remineralization of sinking particulate matter, increases in $\mathrm{B}(\mathrm{OH})_{3}$ are related primarily to decreases in the $\mathrm{pH}$ of seawater, which will change the equilibrium between $\mathrm{B}(\mathrm{OH})_{4}^{-}$and $\mathrm{B}(\mathrm{OH})_{3}$. In addition, conversions from $\mathrm{CO}_{3}^{2-}$ to $\mathrm{HCO}_{3}^{-}$, and from $\mathrm{HCO}_{3}^{-}$to $\mathrm{CO}_{2}$, which also occur when $\mathrm{pH}$ decreases, will also affect the contraction coefficient. Thus, whereas interpretation of the laboratory experiments was complicated primarily by conductivity effects, the value of contraction coefficients in the ocean is mostly dependent on the complex variations in the full carbonate system.

Somewhat paradoxically, in most cases it does appear that $\beta_{\mathrm{R}}^{\text {soln }}$ is smaller than $\beta_{\mathrm{R}}$, and the numerical value is only weakly sensitive to the exact details of the composition change. Thus simple (but incorrect) theoretical models based on simple salt additions may produce approximately correct results. However, these results are not reliable. The true nature of the dependence of the contraction coefficients on biogeochemical processes cannot be simply estimated using simple additions.

\subsection{Regressions onto observational parameters}

Rather than deal with the individual carbonate system components, it may be more straightforward to determine relationships with parameters such as TA and DIC which are unaffected by the details of the equilibrium reactions, but relate to charge and carbon mass. Previous attempts have been made to model density perturbations as a linear function of the variations of a few constituents only (including these), with the coefficients determined semi-theoretically and/or empirically by fits to field data (Brewer and Bradshaw, 1975; Millero et al., 1976, 1978; Millero, 2000; Millero et al., 2008b, 2009). Although Eq. (41) is linear in the constituent concentrations, and hence has a similar mathematical form to these empirical formulas, the complexities of concentration scales and carbonate chemistry resulting from additions (as shown in Table 5) suggest that, rather than proceeding analytically, it is simpler to use the model to generate "data" which can be regressed directly onto constituent concentration changes. An additional advantage of this approach is that this data can be chosen to cover a full range of conditions even if measurements are lacking in some regions of parameter space.

Consider perturbations when $S_{\mathrm{P}}=35$. The model is used to calculate 4500 sets of $\delta \rho_{\mathrm{R}}, \delta S_{\mathrm{R}}^{\text {soln }}$, and $\delta S_{\mathrm{R}}^{*}$ "observations" over a grid of perturbations in TA, DIC, $\mathrm{NO}_{3}^{-}$, and $\mathrm{Si}(\mathrm{OH})_{4}$ within a range of $0 \leq \Delta \mathrm{TA} \leq 0.3 \mathrm{mmol} \mathrm{kg}^{-1}, 0 \leq$ $\Delta \mathrm{DIC} \leq 0.3 \mathrm{mmol} \mathrm{kg}{ }^{-1}, 0 \leq \Delta\left[\mathrm{NO}_{3}^{-}\right] \leq 0.040 \mathrm{mmol} \mathrm{kg}^{-1}$, and $0 \leq \Delta\left[\mathrm{Si}(\mathrm{OH})_{4}\right] \leq 0.160 \mathrm{mmol} \mathrm{kg}^{-1}$ with $\left[\mathrm{Ca}^{2+}\right]$ again 
varying according to Eq. (48) and $S_{\mathrm{P}}$ held fixed. Inspection of the results shows that all three parameters vary quasilinearly with the components of the perturbation. By leastsquares fitting the Eq.

$\delta S_{\mathrm{R}}^{\mathrm{soln}} /\left(\mathrm{mgkg}^{-1}\right)=(7.2 \Delta \mathrm{TA}+47.0 \Delta \mathrm{DIC}$

$\left.+36.5 \Delta\left[\mathrm{NO}_{3}^{-}\right]+96.0 \Delta\left[\mathrm{Si}(\mathrm{OH})_{4}\right]\right) /\left(\mathrm{mmolkg}^{-1}\right)$

models $\delta S_{\mathrm{R}}^{\text {soln }}$ with a standard error (misfit) of $8 \times$ $10^{-2} \mathrm{mg} \mathrm{kg}^{-1}$ and a maximum misfit of $0.3 \mathrm{mg} \mathrm{kg}^{-1}$,

$\delta \rho_{\mathrm{R}} /\left(\mathrm{gm}^{-3}\right)=(41.7 \Delta \mathrm{TA}+3.6 \Delta \mathrm{DIC}$

$\left.+29.3 \Delta\left[\mathrm{NO}_{3}^{-}\right]+38.1 \Delta\left[\mathrm{Si}(\mathrm{OH})_{4}\right]\right) /\left(\mathrm{mmolkg}^{-1}\right)$

models $\delta \rho_{\mathrm{R}}$ with a standard error of $6 \times 10^{-2} \mathrm{~g} \mathrm{~m}^{-3}$ and a maximum misfit of $0.3 \mathrm{~g} \mathrm{~m}^{-3}$, and

$\delta S_{\mathrm{R}}^{*} /\left(\mathrm{mgkg}^{-1}\right)=(-18.1 \Delta \mathrm{TA}-7.1 \Delta \mathrm{DIC}$

$\left.-43.0 \Delta\left[\mathrm{NO}_{3}^{-}\right]+0.1 \Delta\left[\mathrm{Si}(\mathrm{OH})_{4}\right]\right) /\left(\mathrm{mmolkg}^{-1}\right)$

models $\delta S_{\mathrm{R}}^{*}$ with a standard error of $9 \times 10^{-2} \mathrm{mg} \mathrm{kg}^{-1}$ and a maximum misfit of $0.5 \mathrm{mg} \mathrm{kg}^{-1}$. In all cases the misfit error is negligible in practical applications. This justifies the assumption that while TA and DIC include some common species, they provide complementary information and are both useful proxies for explaining the changes in conductivity/salinity/density relationships.

The coefficient of the $\mathrm{Si}(\mathrm{OH})_{4}$ term in Eq. (51) is almost identical to its molar mass, and the coefficient in Eq. (53) is almost zero, as would be expected because of its nonconductive nature. The coefficient in Eq. (52) is relatively low due the relatively bulky/light nature of the molecule in solution. The small deviations from ideal behavior result from higher order nonlinearities in the relationship with the other variables.

For comparison with estimates of $\delta S_{\mathrm{R}}^{\mathrm{dens}}$ from the database described in McDougall et al. (2009), we follow their convention and divide Eq. (52) by $\rho_{\mathrm{R}} \beta_{\mathrm{R}} \approx$ $0.75179 \mathrm{~g} \mathrm{~m}^{-3}\left(\mathrm{~g} \mathrm{~g}^{-1}\right)^{-1}$ (Eq. 5) to get

$\delta S_{\mathrm{R}}^{\mathrm{dens}} /\left(\mathrm{mg} \mathrm{kg}^{-1}\right)=(55.6 \Delta \mathrm{TA}+4.7 \Delta \mathrm{DIC}$

$\left.+38.9 \Delta\left[\mathrm{NO}_{3}^{-}\right]+50.7 \Delta\left[\mathrm{Si}(\mathrm{OH})_{4}\right]\right) /\left(\mathrm{mmol} \mathrm{kg}^{-1}\right)$

Changes in DIC contribute more to $\delta S_{\mathrm{R}}^{\text {soln }}$ than they do to $\delta \rho_{\mathrm{R}}$ (and hence $\delta S_{\mathrm{R}}^{\text {dens }}$ ) or $\delta S_{\mathrm{R}}^{*}$, whereas the opposite is true for the effects of changes in TA. Changes in $\mathrm{NO}_{3}^{-}$affect all three parameters in roughly similar measure. Comparison of the individual terms on the right hand sides suggests that the ratio $\delta \rho_{\mathrm{R}} / \delta S_{\mathrm{R}}^{\text {soln }}$ cannot in general be constant, nor even independent of the constituents.For example, if only $\Delta \mathrm{TA}$ is nonzero, then $\delta \rho_{\mathrm{R}} / \delta S_{\mathrm{R}}^{\text {soln }}=5.7 \mathrm{~g} \mathrm{~m}^{-3}\left(\mathrm{~g} \mathrm{~g}^{-1}\right)^{-1}$, but if only $\Delta$ DIC is nonzero, then $\delta \rho_{\mathrm{R}} / \delta S_{\mathrm{R}}^{\text {soln }}=0.08 \mathrm{~g} \mathrm{~m}^{-3}\left(\mathrm{~g} \mathrm{~g}^{-1}\right)^{-1}$.

Although the predictions of these equations remain to be tested, the coefficients of Eq. (52) at least are recognizeably similar in approximate magnitudes to a previous theoretical estimate (Brewer and Bradshaw (1975), corrected in Millero et al., 1976):

$\delta \rho_{\mathrm{R}} /\left(\mathrm{g} \mathrm{m}^{-3}\right)=\left(53.7 \Delta \mathrm{TA}-9.6 \Delta \mathrm{DIC}+24 \Delta\left[\mathrm{NO}_{3}^{-}\right]\right.$

$\left.+45 \Delta\left[\mathrm{Si}(\mathrm{OH})_{4}\right]\right) /\left(\mathrm{mmol} \mathrm{kg}^{-1}\right)$

estimated in a far simpler manner from less reliable chemical data.

The coefficients vary slightly as a function of salinity. These calculations were repeated for salinities over the range $30 \leq S_{\mathrm{P}} \leq 40$, replacing the $\Delta \mathrm{TA}$ and $\Delta \mathrm{DIC}$ terms with ones for salinity-normalized offsets $\triangle \mathrm{NTA}$ and $\triangle \mathrm{NDIC}$, where these are now the anomalies from $2300 \times\left(S_{\mathrm{P}} / 35\right) \mu \mathrm{mol} \mathrm{kg}{ }^{-1}$ and $2080 \times\left(S_{\mathrm{P}} / 35\right) \mu \mathrm{mol} \mathrm{kg}{ }^{-1}$ respectively. Largest variations are found to occur in the TA coefficient, from -20 to -16 in the $\delta S_{\mathrm{R}}^{*} \mathrm{Eq}$. (53). The numerical variations are no more than \pm 1 for most of the other terms.

\subsection{Calculations on observed hydrographic profiles}

The different biogeochemical parameters are highly correlated in the ocean, and these correlations may simplify the interrelationships between Eqs. (51-54) in real ocean waters. Rather than attempting to parameterize these correlations directly, the above analysis is extended by carrying out calculations for some recent high-quality hydrographic profiles. Results are shown for 5 profiles, selected to be representative of the North Atlantic, Arctic, North Pacific, North Indian, and Southern Oceans (Figs. 6 and 7).

Surface nutrients are low in all profiles except in the Southern Ocean, and surface $\mathrm{pH}$ relatively high, although near or slightly lower than in SSW76 in all except the Indian Ocean (Fig. 6). The Arctic profile has a high DIC, due to cold temperatures, and a high surface TA, which to achieve charge balance is taken to imply higher $\mathrm{Ca}^{2+}$ using Eq. (48). This assumption is probably incorrect as the geochemistry of Arctic surface waters is complicated and greatly affected by river inputs (Bates and Mathis, 2009), but in the absence of direct observations our assumption should provide at least some insight into Arctic density anomalies. Nutrients, TA, and DIC at depth are higher in the North Pacific than in the other profiles. However, deeper North Pacific $\mathrm{pH}$ is lower. Deep nutrient levels are typically higher than surface nutrients in all cases. Inferred $\Delta \mathrm{Ca}^{2+}$ is high in the surface Arctic and Southern Ocean, and high in the deep North Pacific and Indian Ocean.

Calculated constant-conductivity density anomalies $\delta \rho_{\mathrm{R}}$ (Fig. 7a) are highest at depth in the Indian and Pacific Oceans, and uniformly high in the Southern Ocean. $\beta_{\mathrm{R}}^{\text {soln }}$ (Fig. 7b) is variable in surface waters, but is remarkably constant below $200 \mathrm{~m}$, typically around 0.3 to $0.4 \mathrm{~g} \mathrm{~g}^{-1}$ from 200 to $1000 \mathrm{~m}$, rising slightly to between 0.3 and $0.5 \mathrm{~g} \mathrm{~g}^{-1}$ in deeper waters. These values are much lower than $\beta_{\mathrm{R}} \approx 0.735 \mathrm{~g} \mathrm{~g}^{-1}$. 

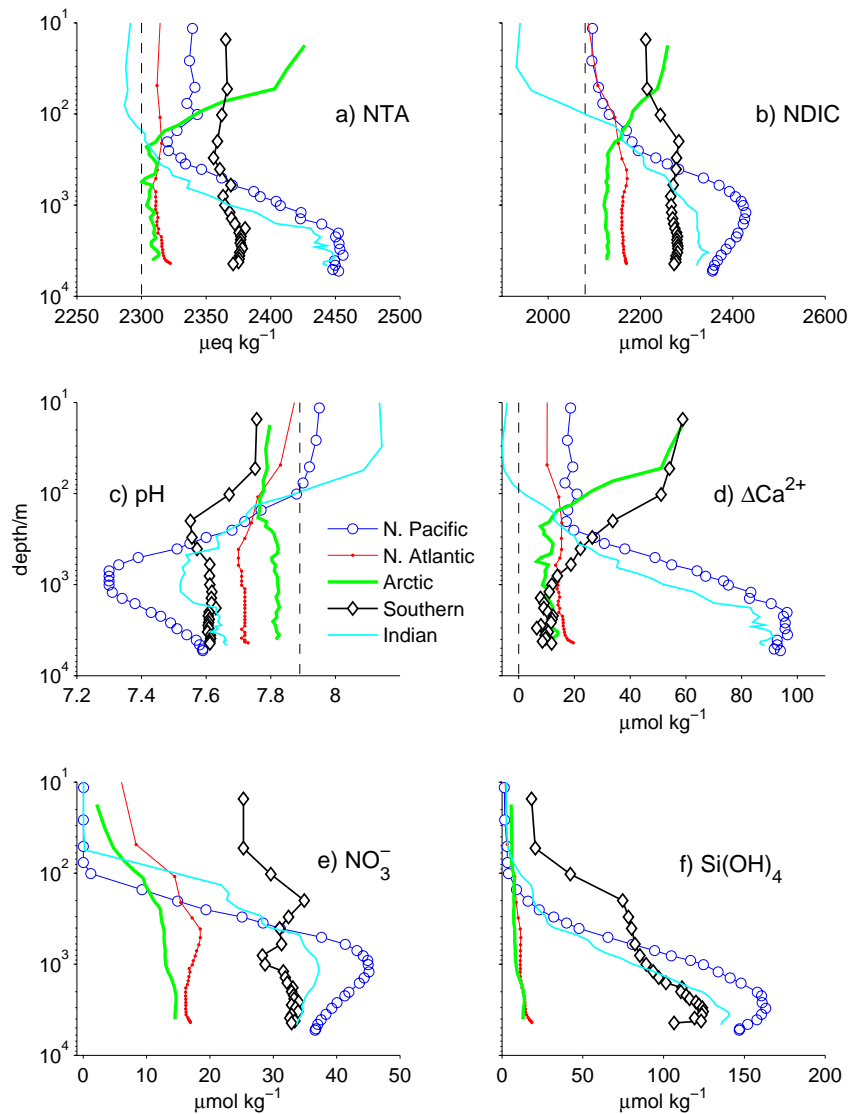

Fig. 6. Composition anomalies for example stations: North Pacific (WOCE line P17, station 34, 37.5 $\mathrm{N}, 135.0^{\circ} \mathrm{W}, 10$ August 2001), North Atlantic (WOCE line A24, station $119,52.73^{\circ} \mathrm{N}, 34.71^{\circ} \mathrm{W}$, 22 June 1997) Arctic (AO94 station 29, 87.16 ${ }^{\circ} \mathrm{N}, 160.71^{\circ} \mathrm{E}$, 17 August1994) Southern Ocean (WOCE line S04, station 29, $62.02^{\circ} \mathrm{S}, 134.18^{\circ} \mathrm{E}, 9$ January 1995$)$ and Northern Indian Ocean (WOCE line I05, station 297, $1.33^{\circ} \mathrm{N}, 80.00^{\circ} \mathrm{E}, 13$ March 1995). (a) Normalized TA for all profiles $\left(\mathrm{NTA}=\mathrm{TA} \times 35 / S_{\mathrm{P}}\right)$. (b) Normalized DIC $\left(\mathrm{NDIC}=\mathrm{DIC} \times 35 / S_{\mathrm{P}}\right)$. (c) $\mathrm{pH}$ on the Total scale. (d) Computed change $\Delta \mathrm{Ca}^{2+}$ (e) $\mathrm{NO}_{3}^{-}$. (f) $\mathrm{Si}(\mathrm{OH})_{4}$. Vertical dashed lines show values in SSW76.

A direct comparison of $\delta S_{\mathrm{R}}^{\text {soln }}$ with $\delta \rho_{\mathrm{R}} / \rho_{\mathrm{R}}$ (Fig. 7c), shows a strong correlation between the two, with the empirical approximation $\beta_{\mathrm{R}}^{\text {soln }} \approx 0.42 \mathrm{~g} \mathrm{~g}^{-1}$ sufficient to model the relationship at all depths to an accuracy of $\pm 3 \mathrm{mg} \mathrm{kg}^{-1}$. The larger variations in directly calculated $\beta_{\mathrm{R}}^{\text {soln }}$ within shallower waters are less important due to the smaller density anomalies, resulting in the increased utility of this simple generalization. Thus as a first approximation the effect of composition changes arising from biogeochemical processes on density is only about $0.42 / 0.735 \approx 0.57$ of the effect arising from a similar mass change of sea salt.

Comparisons of $\delta S_{\mathrm{R}}^{*}$ and $\delta \rho_{\mathrm{R}}$ also show a strong correlation. Although the general trend does show a pro-
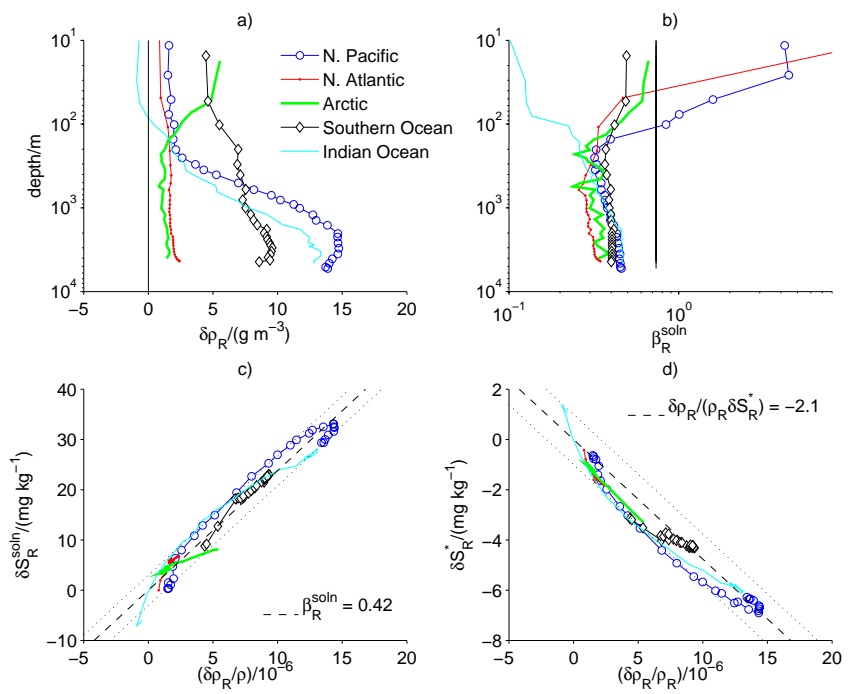

Fig. 7. (a) $\delta \rho_{\mathrm{R}}$ calculated for the hydrographic profiles described in Fig. 6. (b) $\beta_{\mathrm{R}}^{\text {soln }}$ for these profiles. (c) A comparison between model $\delta S_{\mathrm{R}}^{\text {soln }}$ and the normalized density anomaly $\delta \rho_{\mathrm{R}} / \rho$. Dotted lines show a salinity uncertainty of $\pm 3 \mathrm{mg} \mathrm{kg}^{-1}$ above and below the line. (d) A comparison between model $\delta S_{\mathrm{R}}^{*}$ and $\delta \rho_{\mathrm{R}} / \rho$. Dotted line shows an uncertainty of $\pm 1 \mathrm{mg} \mathrm{kg}^{-1}$.

nounced curvature, the linear relationship $\delta \rho_{\mathrm{R}} /\left(\rho_{\mathrm{R}} \delta S_{\mathrm{R}}^{*}\right) \approx$ $-2.1 \mathrm{~g} \mathrm{~g}^{-1}$ is sufficient for predictions with an error of less than $\pm 1 \mathrm{mg} \mathrm{kg}^{-1}$.

\subsection{Comparison with observed $\delta \rho_{\mathrm{R}}$}

The simple relationships found in the previous section, based purely on calculations made with representative hydrographic profiles, can be validated against direct observations of $\delta \rho_{\mathrm{R}}$ (Millero et al., 1976, 1978, 2008b, 2009; McDougall et al., 2009), although the data are more geographically limited. Most of these observations come from the North and South-East Pacific (McDougall et al., 2009). Corresponding observations of $S_{\mathrm{P}}$, TA, DIC, $\mathrm{Si}(\mathrm{OH})_{4}$, and $\mathrm{NO}_{3}^{-}$were obtained either from archived station data, or from published tables in the references. The resulting 610 sets of observables were used to calculate $\delta \rho_{\mathrm{R}}$ using the full model in a fixed conductivity calculation.

Model-predicted $\delta \rho_{\mathrm{R}}$ (Fig. 8) are in good agreement with the observations, with a difference of only $(1.51 \pm$ 4.16) $\mathrm{g} \mathrm{m}^{-3}$ over a range of about $20 \mathrm{~g} \mathrm{~m}^{-3}$ (Table 7). This end-to-end comparison of observations against predictions of the LSEA_DELS model is affected by uncertainties in the observed values of $\delta \rho_{\mathrm{R}}, S_{\mathrm{P}}, \mathrm{NO}_{3}^{-}, \mathrm{Si}(\mathrm{OH})_{4}, \mathrm{TA}$, and DIC (all from datasets obtained up to 30 years ago), as well as uncertainties in the seawater conductivity model of Pawlowicz (2010) and in LIMBETA, the reference seawater composition SSW76 (in particular the specified TA and DIC), the 


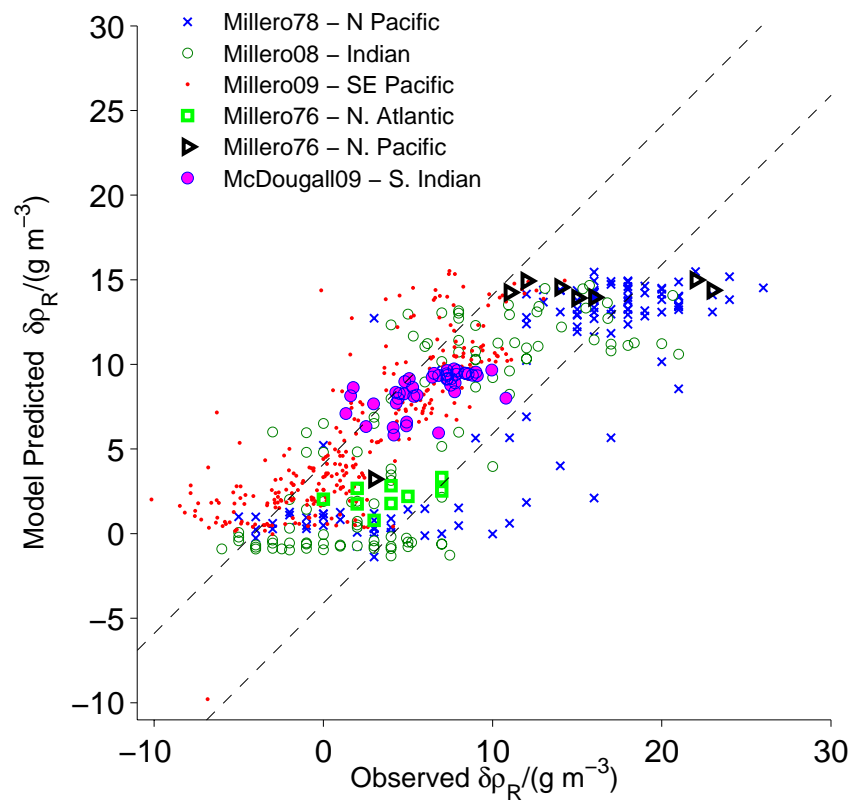

Fig. 8. Comparison between direct ocean observations of $\delta \rho_{\mathrm{R}}$ and model estimates based on measurements of conductivity, nutrients, and carbonate system parameters. The dashed lines show relationships $\delta \rho_{\mathrm{R}}($ model $)=\delta \rho_{\mathrm{R}}($ observed $) \pm 0.004 \mathrm{~g} \mathrm{~m}^{-3}$.

composition model for seawaters of salinities different than $S_{\mathrm{P}}=35$, the carbonate equilibrium model, and the assumption of $\mathrm{CaCO}_{3}$ dissolution incorporated through Eq. (48). However, we emphasize that all of these factors were set a priori. None were varied in any way to tune the agreement in this comparison. Since accuracy of observed $\rho$ alone is generally quoted at $\pm 3 \mathrm{~g} \mathrm{~m}^{-3}$, and the uncertainty in the reference salinity of $\pm 3 \mathrm{mg} \mathrm{kg}^{-1}$ (Pawlowicz, 2010) is equivalent to a density error of about $\pm 2 \mathrm{~g} \mathrm{~m}^{-3}$, it would be unrealistic to expect better agreement.

Although the overall agreement is good, there are some variations in the degree of agreement for different datasets. Individual comparisons for each dataset show standard deviations of around $2 \mathrm{~g} \mathrm{~m}^{-3}$ to $4 \mathrm{~g} \mathrm{~m}^{-3}$, roughly equivalent to the expected measurement variation in $\delta \rho$ observations, but these comparisons also suggest that there may be systematic mean differences between different datasets (Table 7). These systematic differences give rise to offsets in the model/observations comparisons that range from $-3.1 \mathrm{~g} \mathrm{~m}^{-3}$ to $3.6 \mathrm{~g} \mathrm{~m}^{-3}$ depending on the dataset. They are most noticeable for the southeast Pacific dataset (Fig. 8). Assuming that these systematic differences between datasets (which are consistent with the quoted experimental accuracies) are an artifact of the measurement process, we subtract them from the observations in order to better identify the trends (Fig. 9) that occur with changes in $\delta \rho_{\mathrm{R}}$.

A comparison of calculated $\delta S_{\mathrm{R}}^{\text {soln }}$ with dataset-corrected observed $\delta \rho_{\mathrm{R}}$ (Fig. 9a) shows a strong correlation, consis- tent with the empirical $\beta_{\mathrm{R}}^{\text {soln }} \approx 0.42 \mathrm{~g} \mathrm{~g}^{-1}$ found in Sect. 3.5. Similarly, comparison of calculated $\delta S_{\mathrm{R}}^{*}$ and observed $\delta \rho_{\mathrm{R}}$ (Fig. 9b) also shows a strong correlation, again consistent with $\delta \rho_{\mathrm{R}} /\left(\rho_{\mathrm{R}} \delta S_{\mathrm{R}}^{*}\right) \approx-2.1 \mathrm{~g} \mathrm{~g}^{-1}$. The scale factors obtained empirically from analysis of representative profiles from different oceans are therefore consistent with the additional available observations.

\section{Discussion and conclusions}

A detailed mathematical analysis of the haline contraction coefficient reveals a considerable degree of subtle detail that arises when composition perturbations have a relative composition different than that of reference seawater (Fig. 1). A number of different measures of salinity can be made, and each are associated with different definitions of "salinity anomaly". The situation is made more complex by the importance of changes in the chemical equilibria of the carbonate system, which can dominate the calculations of salinity and density changes, as well as the effects of conductivity which partially account for some of these changes.

In spite of this theoretical complexity, model calculations show good agreement with both laboratory experiments in which known additions are made, and with ocean observations when the biogeochemical anomaly is known. Further calculations suggest that the relationship between the different anomalies and the density anomaly $\delta \rho_{\mathrm{R}}$ can be related in a very simple way in the open ocean. The relationships

$\delta S_{\mathrm{R}}^{\text {dens }}=S_{\mathrm{A}}^{\text {dens }}-S_{\mathrm{R}}=\frac{\delta \rho_{\mathrm{R}}}{\rho_{\mathrm{R}}\left[0.735\left(\mathrm{gg}^{-1}\right)\right]}$

between the density salinity $S_{\mathrm{A}}^{\text {dens }}$ (i.e., the absolute salinity of a SSW with the measured density) and the reference salinity $S_{\mathrm{R}}$ (i.e., the absolute salinity of a SSW with the measured conductivity), and

$\delta S_{\mathrm{R}}^{\mathrm{soln}}=S_{\mathrm{A}}^{\mathrm{soln}}-S_{\mathrm{R}}=\frac{\delta \rho_{\mathrm{R}}}{\rho_{\mathrm{R}}\left[0.42\left(\mathrm{gg}^{-1}\right)\right]}$

between the true or solution absolute salinity $S_{\mathrm{A}}^{\text {soln }}$ and the reference salinity provide good agreement for all open ocean observations considered. Density/conductivity measurements can also be used to estimate a preformed salinity $S_{*}$ using the relationship

$\delta S_{\mathrm{R}}^{*}=S_{*}-S_{\mathrm{R}}=-\frac{\delta \rho_{\mathrm{R}}}{\rho_{\mathrm{R}}\left[2.1\left(\mathrm{gg}^{-1}\right)\right]}$

This preformed salinity represents the absolute salinity of seawater with the effects of biogeochemical processes removed. It is therefore a conservative tracer in the ocean, modified by boundary processes but otherwise governed only by advection and mixing.

It should be emphasized that the simplicity of the relationships in Eqs. (55-57) must be a direct consequence of strong correlations between changes in the nutrients and carbonate system parameters, as the sensitivities of $\delta S_{\mathrm{R}}^{*}, \delta \rho_{\mathrm{R}}$, and 
Table 7. Comparison between model-generated and observed estimates of $\delta S_{\mathrm{R}}^{\text {dens }}$.

\begin{tabular}{llcc}
\hline Dataset & Ocean & $\begin{array}{c}\delta \rho_{\mathrm{R}}(\text { model })-\delta \rho_{\mathrm{R}}(\text { observed }) \\
\mathrm{g} \mathrm{m}^{-3}\end{array}$ & $\begin{array}{c}\text { Number of } \\
\text { Samples }\end{array}$ \\
\hline Millero et al. (1976) & N. Atlantic & $-1.57 \pm 2.10$ & 9 \\
Millero et al. (1976) & N. Pacific & $-1.48 \pm 4.33$ & 8 \\
Millero et al. (1978) & N. Pacific & $-3.11 \pm 4.15$ & 123 \\
Millero et al. (2008b) & Indian & $-0.04 \pm 4.15$ & 110 \\
Millero et al. (2009) & S. E. Pacific & $3.63 \pm 2.82$ & 317 \\
McDougall et al. (2009) & S. Indian only & $2.29 \pm 1.85$ & 43 \\
\hline All & All & $1.51 \pm 4.16$ & 610 \\
\hline
\end{tabular}
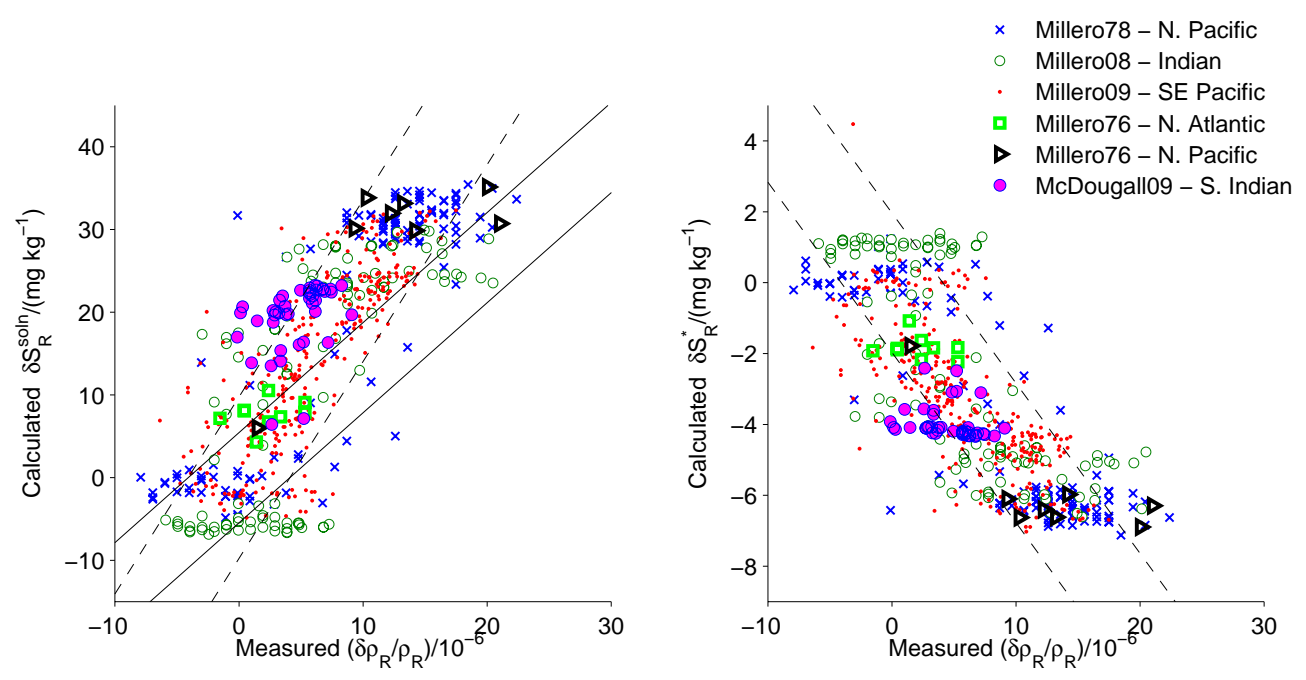

Fig. 9. (a) Comparison between observed $\delta \rho_{\mathrm{R}} / \rho$ and model-calculated $\delta S_{\mathrm{R}}^{\text {soln }}$. Dashed curves show a relationship with $\beta_{\mathrm{R}}^{\text {soln }}=0.42$ offset by density variations of $\pm 0.004 \mathrm{~g} \mathrm{~m}^{-3}$. Solid curves show the same result using $\beta_{\mathrm{R}}$. (b) Comparison between measured $\delta \rho_{\mathrm{R}} / \rho$ and modelcalculated $\delta S_{\mathrm{R}}^{*}$. Dashed curves show a relationship $\delta \rho_{\mathrm{R}} /\left(\rho \delta S_{\mathrm{R}}^{*}\right)=-2.1$, with measured density offsets of $\pm 0.004 \mathrm{~g} \mathrm{~m}^{-3}$.

$\delta S_{\mathrm{R}}^{\text {soln }}$ to different components of the biogeochemical anomalies (Eqs. 51-54) are quite different. That is, the different components have an effect on density which cannot be simply described by the change in dissolved solute mass. However, if observations of nutrients and carbonate parameters are available, then Eqs. (51-54) can be used to estimate the density corrections, and the different types of salinities, without relying on these correlations (at least in the open ocean).

Is there any way to interpret these results in a manner consistent with the heuristic that changes in thermodynamic properties depend only weakly on composition but primarily on the added mass? The obvious source of apparent contradiction is that the calculations carried out here include conductivity effects. This is because the starting point of the relevant calculations was $S_{\mathrm{R}}$ rather than $S_{*}$. Conductivity is a transport property and is sensitive to composition (Pawlowicz, 2010), and so the difference between the effects of added mass and of added charges (which determines the fixed con- ductivity correction $\beta_{\mathrm{R}}^{\text {soln }}$ ) might also be sensitive to composition. This is seen in the laboratory measurements (Fig. 4). However, the generally small differences between $\beta_{\mathrm{R}}^{\text {soln }}$ for the fixed conductivity case and $\beta_{*}^{\text {soln }}$ for the fixed chlorinity case in Table 5 suggest that, for the specific case of biogeochemical perturbations in the ocean, these conductivity effects are not large. As was found by Pawlowicz (2010), the constituents of biogeochemical perturbations are relatively unconductive. Typically $\left|\delta S_{\mathrm{R}}^{*}\right|$ is less than $0.2\left|\delta S_{*}^{\text {soln }}\right|$, so even the largest composition-related variations in $\delta S_{\mathrm{R}}^{*}$ would have only small effects on $\delta S_{\mathrm{R}}^{\text {soln }}$.

Instead, the critical issue appears to be that the definition of salinity and its perturbation $\delta S_{*}^{\text {soln }}$ is itself not completely consistent with the idea of added mass $\delta S_{*}^{\text {add }}$, because the latter does not properly account for the mass of $\mathrm{H}_{2} \mathrm{O}$ and $\mathrm{O}_{2}$ involved in chemical reactions within the water that modify the chemical forms actually added. This is even more true for $\delta S_{\mathrm{R}}^{\text {soln }}$, which in addition is affected by conductivity. 
a)

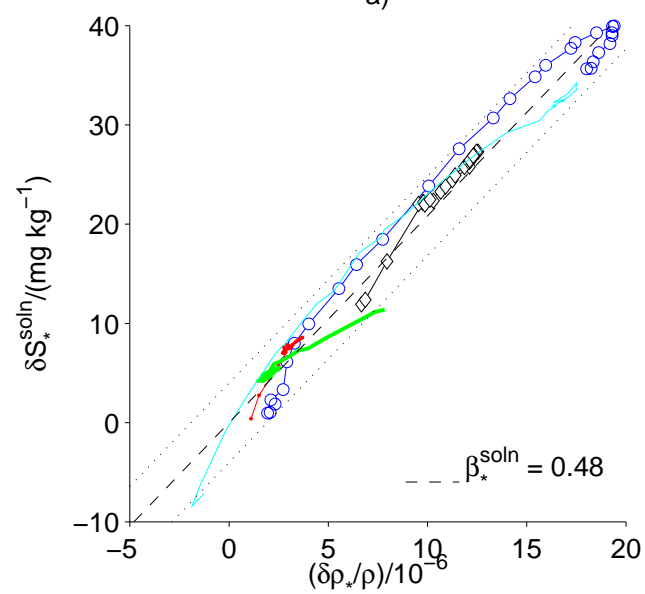

b)

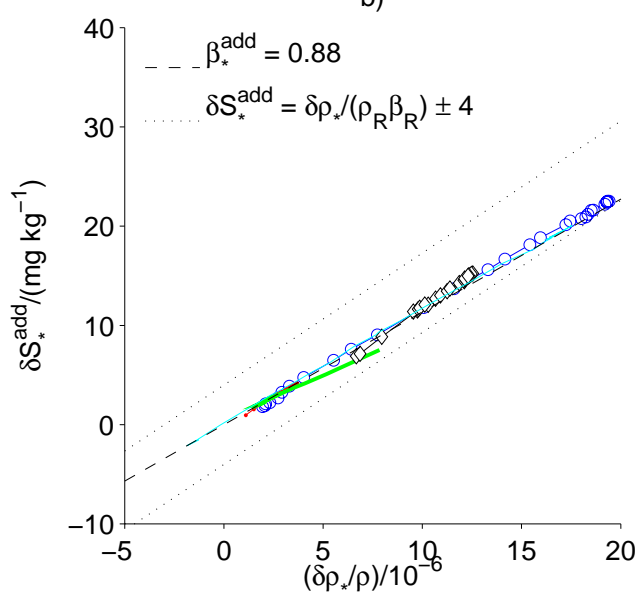

Fig. 10. Calculated salinity/density relationships for example profiles. Legend as for Figs. 5 and 7. (a) $\delta S_{*}^{\text {soln }} / \delta \rho_{*}$ relationship. (b) $\delta S_{*}^{\text {add }} / \delta \rho_{*}$ relationship. Dotted lines show salinity uncertainty of $\pm 4 \mathrm{mg} \mathrm{kg}^{-1}$ above and below the lines.

Increases in deep ocean DIC arise primarily from the production of $\mathrm{CO}_{2}$ by remineralization of organic carbon, and from $\mathrm{CO}_{3}^{2-}$ when $\mathrm{CaCO}_{3}$ dissolves and dissociates. However, Table 5 shows that the largest composition change in the ocean is an increase in $\mathrm{HCO}_{3}^{-}$. Remineralization of organic nitrogen also produces $\mathrm{HNO}_{3}$, which dissociates into $\mathrm{H}^{+}$and $\mathrm{NO}_{3}^{-}$. Increases in the concentration of $\mathrm{Si}(\mathrm{OH})_{4}$ occur due to the dissolution and hydration of solid $\mathrm{SiO}_{2}$. Thus the true amount of mass from biogeochemical processes added to seawater must be less than $\delta S_{*}^{\text {soln }}$. Note that these difficulties do not affect density calculations, which are based entirely on the final chemical forms of added material. However, since they affect the salinity measure they must be reflected in changes to the relevant haline contraction coefficient.

The true mass of material added to a water with preformed salinity $S_{*}$ from these biogeochemical processes, $\delta S_{*}^{\text {add }}$, can be estimated as

$$
\begin{aligned}
\delta S_{*}^{\text {add }} & =M_{\mathrm{C}} \Delta\left[\mathrm{CO}_{2}\right] \\
& +M_{\mathrm{H}} \Delta\left[\mathrm{H}^{+}\right]+M_{\mathrm{N}} \Delta\left[\mathrm{NO}_{3}^{-}\right] \\
& +M_{\mathrm{Ca}} \Delta\left[\mathrm{Ca}^{2+}\right]+M_{\mathrm{CO}_{3}} \Delta\left[\mathrm{CO}_{3}^{2-}\right] \\
& +M_{\mathrm{SiO}_{2}} \Delta\left[\mathrm{Si}(\mathrm{OH})_{4}\right]
\end{aligned}
$$

where $M_{X}$ is the molar mass for formula $X$. This equation is a modification of the definition of salinity (Eq. 2) because it attempts to model only the material added to seawater, rather than the actual composition of the mixture. Thus the mass of $\mathrm{O}$ in remineralization of $\mathrm{C}$ and $\mathrm{N}$ is not included in mass calculations because its primary source is the dissolved $\mathrm{O}_{2}$ gas already in water. Neither is the mass of added $2 \mathrm{H}_{2} \mathrm{O}$ included with increases in $\mathrm{Si}(\mathrm{OH})_{4}$. The equation also does not take into account any composition changes that result from changing equilibria in the carbonate system. In all cases these changes will incorporate extra mass which is converted from constituents already within the seawater. Note that remineralization also results in the production of a small amount of $\mathrm{H}_{2} \mathrm{O}$, which will dilute the seawater. As this dilution will change salinities by much less than $1 \mathrm{mg} \mathrm{kg}^{-1}$ it is ignored here.

Equation (58) for $\delta S_{*}^{\text {add }}$ can be simplified by taking $\Delta\left[\mathrm{H}^{+}\right]=\Delta\left[\mathrm{NO}_{3}^{-}\right]$and $\Delta\left[\mathrm{Ca}^{2+}\right]=\Delta\left[\mathrm{CO}_{3}^{2-}\right](=(\Delta \mathrm{TA}+$ $\left.\Delta\left[\mathrm{NO}_{3}^{-}\right]\right) / 2$ from Eq. 48$)$, consistent with knowledge of biogeochemical processes. Then, using the definitions of TA and DIC (Eqs. 46-47), substituting, rearranging, and incorporating the numerical values for molar masses (Pawlowicz, 2010):

$$
\begin{aligned}
& \delta S_{*}^{\text {add }} /\left(\mathrm{mgkg}^{-1}\right)=\left(-M_{\mathrm{C}}+M_{\mathrm{CO}_{3}}+M_{\mathrm{Ca}}\right) / 2 \Delta \mathrm{TA} \\
& +M_{\mathrm{C}} \Delta \mathrm{DIC}+\left(\left(-M_{\mathrm{C}}+M_{\mathrm{CO}_{3}}+M_{\mathrm{Ca}}\right) / 2+M_{\mathrm{H}}+M_{\mathrm{N}}\right) \\
& \Delta\left[\mathrm{NO}_{3}^{-}\right]+M_{\mathrm{SiO}_{2}} \Delta\left[\mathrm{Si}(\mathrm{OH})_{4}\right] \\
& =\left(44.0 \Delta \mathrm{TA}+12.0 \Delta \mathrm{DIC}+59.1 \Delta\left[\mathrm{NO}_{3}^{-}\right]\right. \\
& \left.+60.1 \Delta\left[\mathrm{Si}(\mathrm{OH})_{4}\right]\right) /\left(\mathrm{mmolkg}^{-1}\right)
\end{aligned}
$$

For comparison, from Eqs. (51-53) we have a difference between the preformed and solution salinities of:

$$
\begin{aligned}
& \delta S_{*}^{\text {soln }} /\left(\mathrm{mgkg}^{-1}\right)=\delta S_{\mathrm{R}}^{\text {soln }}-\delta S_{\mathrm{R}}^{*} \\
& =\left(25.3 \Delta \mathrm{TA}+54.2 \Delta \mathrm{DIC}+79.5 \Delta\left[\mathrm{NO}_{3}^{-}\right]\right. \\
& \left.+95.9 \Delta\left[\mathrm{Si}(\mathrm{OH})_{4}\right]\right) /\left(\mathrm{mmolkg}^{-1}\right)
\end{aligned}
$$

associated with a total density change of:

$$
\begin{aligned}
& \delta \rho_{*} /\left(\mathrm{gm}^{-3}\right)=\delta \rho_{\mathrm{R}}-\rho_{\mathrm{R}} \beta_{\mathrm{R}} \delta S_{\mathrm{R}}^{*} \\
& =\left(55.4 \Delta \mathrm{TA}+8.9 \Delta \mathrm{DIC}+61.7 \Delta\left[\mathrm{NO}_{3}^{-}\right]\right. \\
& \left.+38.2 \Delta\left[\mathrm{Si}(\mathrm{OH})_{4}\right]\right) /\left(\mathrm{mmolkg}^{-1}\right)
\end{aligned}
$$

The relationship between $\delta S_{*}^{\text {soln }}$ and $\delta \rho_{*}$ for the hydrographic profiles considered earlier can be modelled with $\beta_{*}^{\text {soln }} \approx 0.48 \mathrm{~g} \mathrm{~g}^{-1}$ (Fig. 10a), which is only a little different 
than the value of $\beta_{\mathrm{R}}^{\text {soln }} \approx 0.42 \mathrm{~g} \mathrm{~g}^{-1}$ found for the $\delta S_{\mathrm{R}}^{\text {soln }} / \delta \rho_{\mathrm{R}}$ relationship (Fig. 7c). Removing the effects of conductivity has only a small effect on the salinity/density relationship, as expected on the basis of the discussion above. However, the $\beta_{*}^{\text {add }} \approx 0.88 \mathrm{~g} \mathrm{~g}^{-1}$ relationship between $\delta S_{*}^{\text {add }}$ and $\delta \rho_{*}$ (Fig. 10b) is very different. Not only does the relationship exhibit far less curvature than seen in Figs. 7c,d, and 10a, but the results can also be modelled (albeit with a bias of up to $4 \mathrm{mg} \mathrm{kg}^{-1}$ ) using $\beta_{\mathrm{R}}$. The ratios of individual terms in Eqs. (59) and (61) are still not related by this (or any other) single scaling factor, nor is $\delta S_{*}^{\text {add }}$ exactly equal to $\delta S_{*}^{\text {dens }}$ $\left(=\delta S_{\mathrm{R}}^{\text {dens }}-\delta S_{\mathrm{R}}^{*}\right)$, so there is still some sensitivity to the exact details of the perturbation. However, for ocean profiles correlations between the different constituents again reduce the variability. The final relationship

$S_{\mathrm{A}}^{\mathrm{add}}-S_{*}=\frac{\delta \rho *}{\rho *\left[0.88\left(\mathrm{gg}^{-1}\right)\right]}$

between added-mass and preformed salinities is then approximately (and narrowly) consistent with the heuristic that added mass alone is the most important factor affecting density (exact equivalence would require a numerical parameter in the denominator of $0.735 \mathrm{~g} \mathrm{~g}^{-1}$ ). If we consider changes relative to reference conditions we find

$S_{\mathrm{A}}^{\mathrm{add}}-S_{\mathrm{R}} \approx \frac{\delta \rho_{\mathrm{R}}}{\rho_{\mathrm{R}}\left[0.95\left(\mathrm{gg}^{-1}\right)\right]}$

(where the second form is obtained after using $\delta \rho_{*}=\delta \rho_{\mathrm{R}}-$ $\rho_{\mathrm{R}} \beta_{\mathrm{R}} \delta S_{\mathrm{R}}^{*}$, substituting Eq. (57) and taking $\rho_{\mathrm{R}} \approx \rho_{*}$ ). These show a greater divergence from the heuristic.

Thus the basic conclusion is that the density of seawater does in fact change roughly (i.e. within typical measurement error) in proportion to the added mass of solutes from the biogeochemical processes, as long as they are correlated in the specific ratios seen in the ocean, but that this result may have only a restricted applicability in practical calculations involving field measurements! This is largely because the (intuitive) definition of salinity, a simple summation of the inorganic ions present in solution at reference conditions (Eq. 2), takes into account chemical reactions that modify the added constituents into other (generally heavier) molecular forms. This factor was not generally present in the laboratory experiments that were carried out. However, unlike the case for many of the laboratory experiments, corrections that arise from conductivity changes result in a much smaller discrepancy because the products of ocean biogeochemical processes are relatively unconductive.

Potentially this makes conductivity/salinity/density relationships to be used in reducing ocean measurements much more complex. In addition to the traditionally measured $S_{\mathrm{P}}$ and the recently defined $S_{\mathrm{R}}$ which more usefully describes SSW, a hierarchy of different salinity variables $\left(S_{\mathrm{A}}^{\text {soln }}, S_{\mathrm{A}}^{\text {dens }}\right.$, $S_{\mathrm{A}}^{\text {add }}$, and $S_{*}$ ) are required to understand spatial and temporal variations in the ocean. Each of these new variables is most suitable for a different particular purpose. $S_{\mathrm{A}}^{\text {soln }}$ represents the salinity best when details of the complete composition are being investigated. $S_{\mathrm{A}}^{\text {dens }}$ is most useful as the state variable in the equation of state to provide more accurate thermodynamic information. $S_{*}$ has a role as a conservative tracer. $S_{\mathrm{A}}^{\text {add }}$ is in itself not important, except that keeping track of $S_{*}$ and $\delta S_{*}^{\text {add }}$ may be useful in investigations of biogeochemical processes, with their sum being useful as an approximation to $S_{\mathrm{A}}^{\text {dens }}$. Fortunately, the model results described here suggest that any of these parameters, and the conversions between them, can be obtained through measurements of conductivity and density using Eqs. (55, 56, 57, 62 and 63), or measurements of conductivity and carbonate system parameters and nutrients using Eqs. (51, 52, 53, 54, 59, 60 and 61).

Recall that all the formulas here have been developed based on composition anomalies from SSW as specified by the SSW76 composition model, whose DIC value differs from that implied in the Reference Composition (RC; Millero et al., 2008a). The effects of using a different DIC reference can be illustrated as follows. As long as the change in the reference state is "small" (which is the case here, as the range of oceanic variation in DIC is much larger than the change we are considering), the coefficients in Eqs. (51-54 and 59-61) do not change significantly. A decrease in the reference level of DIC is essentially similar in effect to increasing the $\triangle \mathrm{DIC}$ value used in these formulas by $117 \mu \mathrm{mol} \mathrm{kg}{ }^{-1}$.

Thus, using the RC value for DIC increases $\delta S_{\mathrm{R}}^{\text {soln }}$ by $5 \mathrm{mg} \mathrm{kg}^{-1}$, increases $\rho_{\mathrm{R}}$ by $0.4 \mathrm{~g} \mathrm{~m}^{3}$, and decreases $\delta S_{\mathrm{R}}^{*}$ by $0.7 \mathrm{mg} \mathrm{kg}^{-1}$. Effectively this would move all the calculated curves in Figs. 7c and 9a upwards by 5 units and rightwards by 0.4 units, those in Figs. $7 \mathrm{~d}$ and $9 \mathrm{~b}$ downwards by 0.7 units and rightwards by 0.4 units, all points in Fig. 8 upwards by 0.4 units, all curves in Fig. 10a upwards by 5.5 and rightwards by 0.9 units, and all curves in Fig. 10b upwards by 1 and rightwards by 0.9 units. This would imply that some of relationships in Eqs. (55-57, 62 and 63) would be better modelled with a non-zero intercept. The fact that the linear correlations obtained using SSW76 as a reference go through the origin (e.g., in Figs. 7c,d and 10) in spite of the composition-dependent scalings in the anomaly Eqs. is then a fortuitous result that simplifies all interpretations.

However, one must consider how to apply the results obtained here in applications that use the fixed RC and the associated Reference Salinity Scale used by TEOS-10. Fortunately, the differences in numerical salinity values are relatively small. The relations obtained here are linear in the composition anomalies, and RC lies within that linear range. Thus the anomalies predicted by these relations may be added directly to reference salinities ("TEOS-10 $S_{\mathrm{R}}$ ") in this standardized reference state.

One might consider the possibility of "improving" the TEOS-10 formulation by modifying the factor $u_{\mathrm{PS}}$ in Eq. (3), so that the calculated $S_{\mathrm{R}}$ reflects the newer estimate of the carbonate components of SSW considered here. This would 
mean that global salinity values would be increased by a scale factor of $35.17124 / 35.16504 \approx 1.000176$. However, doing so is not advisable for a number of practical reasons (Wright et al., 2011). First, the change is not larger than the actual uncertainty in the RC arising from other issues (Millero et al., 2008a; Seitz et al., 2010; Lee et al., 2010), and so the resulting salinity values may not reflect the true absolute salinity any better. Second, even if the new value was more accurate, the size of the change would merely change estimates of global ocean solute mass by about a factor of about $2 \times 10^{-4}$, which is not important. Third, it raises the possibility of future confusion about the meaning of numerical salinity values as more information is obtained about the composition of SSW, without in any way improving the utility of these anomaly formulas for investigating spatial and temporal changes in the ocean. Finally, the newly re-defined $S_{\mathrm{R}}$ would no longer be the correct numerical argument in the numerical formulation of TEOS-10, which would then also have to be updated.

Several other factors still require clarification. First, at what level of measurement precision do the correction factors which are the subject of this paper become important? Second, just how useful is $S_{\mathrm{A}}^{\text {dens }}$ as a variable for predicting thermodynamic properties other than densities? A companion paper (Wright et al., 2011) considers these points in greater detail, according to our best available knowledge. Briefly, in the open ocean these salinity corrections are at most around $0.03 \mathrm{~g} \mathrm{~kg}^{-1}$, but they can approach $0.09 \mathrm{~g} \mathrm{~kg}^{-1}$ in coastal areas. Use of these corrections does not appear to significantly degrade the prediction of thermodynamic properties and in some cases improves them. Third, although temperature effects were briefly considered and found to be small, LIMBETA is not yet able to estimate pressure effects. Since the equation of state is nonlinear density calculations at atmospheric pressure are not necessarily the same as those at depth and this effect may be important. However, some preliminary studies of this problem are also reported in Wright et al. (2011) and although they must still be fully validated the computed effects seem small enough to be practically unimportant. Another possible problem is that dominant biogeochemical processes in the open ocean are not necessarily the same as those occurring on continental shelves or marginal seas, and this may affect the results in those areas (although in practise the correction itself will be less important as the known density variations are larger). In addition, the calculations are limited to the effects of inorganic material only. As concentrations of dissolved organic material in the open ocean are typically in the range of 0.5 to $2 \mathrm{mg} \mathrm{kg}^{-1}$, and may be much higher in coastal regions (Millero, 2006), they would be in excess of the threshold of $1 \mathrm{mg} \mathrm{kg}^{-1}$ used in defining model components, and hence may affect the results. Further model/data comparisons should be carried out in coastal and marginal seas, as well as in oceanic areas in which density anomalies have not yet been measured.
Acknowledgements. Work by RP was supported by the Natural Sciences and Engineering Research Council of Canada (NSERC) under grant 194270-06. FJM acknowledges the support of the Oceanographic section of the National Science Foundation (NSF) and National Oceanic and Atmospheric Administration (NOAA). Profile data was acquired from the CLIVAR and Carbon Hydrographic Data Office (CCHDO) at http://whpo.ucsd.edu. This paper contributes to the tasks of SCOR/IAPSO Working Group 127.

Edited by: T. McDougall

\section{References}

Bates, N. R. and Mathis, J. T.: The Arctic Ocean marine carbon cycle: evaluation of air-sea $\mathrm{CO}_{2}$ exchanges, ocean acidification impacts and potential feedbacks, Biogeosciences, 6, 2433-2459, 2009 ,

http://www.biogeosciences.net/6/2433/2009/.

Brewer, P. G. and Bradshaw, A.: The effect of the non-ideal composition of seawater on salinity and density, J. Mar. Res., 33, 157-175, 1975.

Chen, C. T. and Millero, F. J.: Precise thermodynamical properties for natural waters covering only the limnological range, Limnol. Oceanogr., 31, 657-662, 1986.

Chen, C.-T. A.: Shelf-vs. dissolution-generated alkalinity above the chemical lysocline, Deep Sea Res. Pt. II, 49, 5365-5375, 2002.

de Villiers, S.: Excess dissolved $\mathrm{Ca}$ in the deep ocean: a hydrothermal hypothesis, Earth Planet. Sci. Lett., 164, 627-641, 1998.

Dickson, A. G., , Sabine, C. L., and Christian, J. R.: Guide to best practices for ocean $\mathrm{CO}_{2}$ measurements, PICES Special Publication 3, 2007.

Duedall, I. W., Dayal, R., and Willey, J. D.: The partial molal volume of silicic acid in $0.725 \mathrm{~m} \mathrm{NaCl}$, Geochim. Cosmochim. Ac., 40, 1185-1189, 1976.

Feistel, R.: A Gibbs Function for Seawater Thermodynamics for -6 to $80^{\circ} \mathrm{C}$ and Salinity up to $120 \mathrm{~g} \mathrm{~kg}^{-1}$, Deep Sea Res. Pt. I, 55, 1619-1671, 2008.

Feistel, R.: Extended equation of state for seawater at elevated temperature and salinity, Desalination, 250, 14-18, 2010.

Feistel, R. and Marion, G. M.: A Gibbs-Pitzer function for highsalinity seawater thermodynamics, Prog. Oceanogr., 74, 515539, 2007.

Hershey, J. P., Sotolongo, S., and Millero, F. J.: Densities and Compressibilities of Aqueous Sodium Carbonate and Bicarbonate from 0 to $45^{\circ} \mathrm{C}$, J. Soln. Chemistry, 12, 233-254, 1983.

IOC, SCOR, and IAPSO: The international thermodynamic equation of seawater - 2010: Calculation and use of thermodynamic properties, Manual and Guides No. 56, Intergovernmental Oceanographic Commission, UNESCO (English), available from http://www.TEOS-10.org, 2010.

Lee, K., Kim, T.-W., Byrne, R., Millero, F. J., Feely, R. A., and Liu, Y.-M.: The universal ratio of boron to chlorinity for the North Pacific and North Atlantic oceans, Geochim. Cosmochim. Ac., 74, 1801-1811, 2010.

Lewis, E. L. and Perkin, R. G.: Salinity: Its definition and Calculation, J. Geophys. Res., 83, 466-478, 1978.

Lo Surdo, A., Alzola, E. M., and Millero, F. J.: The ( $p, V, T)$ properties of concentrated aqueous electrolytes I. Densities and ap- 
parent molar volumes of $\mathrm{NaCl}, \mathrm{Na}_{2} \mathrm{SO}_{4}, \mathrm{MgCl}_{2}$, and $\mathrm{MgSO}_{4}$ solutions from $0.1 \mathrm{~mol} \cdot \mathrm{kg}^{-1}$ to saturation and from 273.15 to 323.15 K, J. Chem. Thermodynamics, 14, 649-662, 1982.

Mao, S. and Duan, Z:: The $P, V, T, x$ properties of binary aqueous chloride solutions up to $T=573 \mathrm{~K}$ and $100 \mathrm{MPa}$, J. Chem. Thermodynamics, 40, 1046-1063, 2008.

McDougall, T. J., Jackett, D. R., and Millero, F. J.: An algorithm for estimating Absolute Salinity in the global ocean, Ocean Sci. Discuss., 6, 215-242, 2009,

http://www.ocean-sci-discuss.net/6/215/2009/.

Millero, F. J.: The partial molal volumes of electrolytes in aqueous solutions, in: Water and aqueous solutions, edited by: Horne, R. A., chap. 13, pp. 519-564, Wiley-Interscience, New York, 1972.

Millero, F. J.: The Physical Chemistry of Estuaries, in: Marine Chemistry in the Coastal Environment, edited by Church, T. M., pp. 25-55, American Chemical Society, 1975.

Millero, F. J.: Thermodynamics of the carbon dioxide system in the oceans, Geochim. Cosmochim. Ac., 59, 661-677, 1995.

Millero, F. J.: Effect of changes in the composition of seawater on the density-salinity relationship, Deep Sea Res. Pt. I, 47, 15831590, 2000.

Millero, F. J.: The Physical Chemistry of Natural Waters, WileyInterscience, New York, 2001.

Millero, F. J.: Chemical Oceanography, CRC Press, Boca Raton, FL., 3. Edn., 2006.

Millero, F. J. and Huang, F.: The density of seawater as a function of salinity ( 5 to $70 \mathrm{~g} \mathrm{~kg}^{-1}$ ) and temperature (273.15 to $363.15 \mathrm{~K}$ ), Ocean Sci., 5, 91-100, 2009, http://www.ocean-sci.net/5/91/2009/.

Millero, F. J. and Lepple, F. K.: The density and expansibility of artificial seawater solutions from 0 to $40^{\circ} \mathrm{C}$ and 0 to 21 chlorinity, Mar. Chem., 1, 89-104, 1972.

Millero, F. J., Hoff, E. V., and Kahn, L.: The effect of pressure on the ionization of Water at Various Temperatures from MolalVolume Data, J. Soln. Chemistry, 1, 309-327, 1972.

Millero, F. J., Gonzalez, A., Brewer, P. G., and Bradshaw, A.: The density of North Atlantic and North Pacific deep waters, Earth Planet. Sci. Lett, 32, 468-472, 1976.

Millero, F. J., Laferriere, A. L., and Chetirkin, P. V.: The partial molal volumes of electrolytes in $0.725 \mathrm{~m}$ Sodium Chloride solutions at $25^{\circ} \mathrm{C}$, J. Phys. Chem, 81, 1737-1745, 1977.

Millero, F. J., Forsht, D., and Means, D.: The Density of North Pacific Ocean Waters, J. Geophys. Res., 83, 2359-2364, 1978.
Millero, F. J., Feistel, R., Wright, D. G., and McDougall, T. J.: The composition of Standard Seawater and the definition of the Reference-Composition Salinity Scale, Deep Sea Res. Pt. 1, 55, 50-72, 2008a.

Millero, F. J., Waters, J., Woosley, R., Huang, F., and Chanson, M.: The effect of composition on the density of Indian Ocean waters, Deep Sea Res. Pt. I, 55, 460-470, 2008 b.

Millero, F. J., Huang, F., Williams, N., Waters, J., and Woosley, R.: The effect of composition oin the density of South Pacific Ocean waters, Mar. Chem., 114, 56-62, 2009.

Monnin, C.: Density calculations and concentration scale conversions for natural waters, Computers and Geosciences, 20, 14351445, 1994.

Pavlova, G. Y., Tishchenko, P. Y., and Nedashkovskii, A. P.: Distribution of Alkalinity and Dissolved Calcium in the Sea of Okhotsk, Oceanology, 48, 23-32, 2008.

Pawlowicz, R.: Calculating the conductivity of natural waters, Limnol. Oceanogr. Methods, 6, 489-501, 2008.

Pawlowicz, R.: A model for predicting changes in the electrical conductivity, practical salinity, and absolute salinity of seawater due to variations in relative chemical composition, Ocean Sci., 6, 361-378, 2010, http://www.ocean-sci.net/6/361/2010/.

Pierrot, D. and Millero, F. J.: The Apparent Molal Volume and Compressibility of Seawater fit to the Pitzer Equations, J. Soln. Chem., 29, 719-742, 2000.

Seitz, S., Spitzer, P., and Brown, R. J. C.: CCQM-P111 study on traceable determination of Practical Salinity and mass fraction of major seawater components, Accred. Qual. Assur., 15, 9-17, doi:10.1007/s00769-009-0578-8, 2010.

UNESCO: Background papers and supporting data on the International Equation of State of Seawater 1980, Unesco Technical Papers in Marine Science 38, Paris, 1981a.

UNESCO: Background papers and supporting data on the Practical Salinity Scale 1978, Unesco Technical Papers in Marine Science 37, Paris, 1981b.

Ward, G. K. and Millero, F. J.: The Effect of Pressure on the Ionization of Boric Acid in Aqueous Solutions from Molal-Volume Data, J. Soln. Chemistry, 3, 417-430, 1974.

Watanabe, H. and Iizuka, K.: The influence of dissolved gases on the density of water, Metrologia, 21, 19-26, 1985.

Wright, D. G., Pawlowicz, R., McDougall, T. J., and Feistel, R.: Absolute Salinity, "Density Salinity" and the ReferenceComposition Salinity Scale: Present and Future Use in the Seawater Standard TEOS-10, Ocean Sci., 7, 1-26, 2011, http://www.ocean-sci.net/7/1/2011/. 